\title{
Using ERA-Interim reanalysis for creating datasets of energy-relevant climate variables
}

\author{
Philip D. Jones ${ }^{1,4}$, Colin Harpham ${ }^{1}$, Alberto Troccoli ${ }^{2,5}$, Benoit Gschwind ${ }^{3}$, Thierry Ranchin ${ }^{3}$, \\ Lucien Wald $^{3}$, Clare M. Goodess ${ }^{1}$, and Stephen Dorling ${ }^{2}$ \\ ${ }^{1}$ Climatic Research Unit (CRU), School of Environmental Sciences,University of East Anglia, \\ Norwich, NR4 7TJ, UK \\ ${ }^{2}$ School of Environmental Sciences, University of East Anglia, Norwich, NR4 7TJ, UK \\ ${ }^{3}$ MINES ParisTech, PSL Research University, O.I.E. - Centre Observation, Impacts, Energy, \\ 06904 Sophia Antipolis, France \\ ${ }^{4}$ Center of Excellence for Climate Change Research, Department of Meteorology, King Abdulaziz University, \\ Jeddah, Saudi Arabia \\ ${ }^{5}$ World Energy \& Meteorology Council (WEMC), Norwich, NR4 7TJ, UK \\ Correspondence to: Philip D. Jones (p.jones@uea.ac.uk)
}

Received: 16 December 2016 - Discussion started: 6 January 2017

Revised: 11 May 2017 - Accepted: 25 May 2017 - Published: 21 July 2017

\begin{abstract}
The construction of a bias-adjusted dataset of climate variables at the near surface using ERA-Interim reanalysis is presented. A number of different, variable-dependent, bias-adjustment approaches have been proposed. Here we modify the parameters of different distributions (depending on the variable), adjusting ERAInterim based on gridded station or direct station observations. The variables are air temperature, dewpoint temperature, precipitation (daily only), solar radiation, wind speed, and relative humidity. These are available on either 3 or $6 \mathrm{~h}$ timescales over the period 1979-2016. The resulting bias-adjusted dataset is available through the Climate Data Store (CDS) of the Copernicus Climate Change Data Store (C3S) and can be accessed at present from ftp://ecem.climate.copernicus.eu. The benefit of performing bias adjustment is demonstrated by comparing initial and bias-adjusted ERA-Interim data against gridded observational fields.
\end{abstract}

\section{Introduction}

Climate/weather information has been widely used in a number of climate-related impact sectors (e.g. agriculture, water, and energy) for decades. Increasingly, users are moving beyond the use of station observations to the use of gridded products, especially meteorological reanalysis datasets. These are reconstructions of past climate produced through the blending of observations with physical/numerical models which have been developed explicitly for climate monitoring and research (Compo et al., 2011; Dee et al., 2011; Hersbach et al., 2015). How good ERA-Interim is for climate monitoring has been extensively addressed recently by Simmons et al. (2017). This study shows excellent agreement for global- and continental-scale trends in surface air temperatures over land with conventional station-based datasets (see Jones, 2016, for details of these datasets).
Reanalyses have the specific advantage of being spatially and temporally complete through the process of physi$\mathrm{cal} /$ dynamic representation of the climate system which provides internally consistent fields across most surface atmospheric variables as well as in the atmospheric column up to the stratosphere (Compo et al., 2011). The present paper deals with the use of reanalysis for the production of datasets of climate variables relevant to the energy sector. The work took place within the European Climatic Energy Mixes (ECEM) project, a Sectoral Information Service (SIS) part of the Copernicus Climate Change Service (C3S). This project is primarily focused on users in the energy sector who are interested in sub-daily (e.g. $6 \mathrm{~h}$ ) and daily variability for the following variables at the near surface: air temperature, dewpoint temperature, precipitation, solar radiation, wind speed, and relative humidity. Despite this choice of 
variables being of primary relevance to the energy sector, it is likely that the results will also be of use to other sectors (particularly water and agriculture).

Because reanalyses are computed on a model grid, inevitably there will be differences when they are compared to station observations. Differences are not solely related to scales: reanalyses are dependent on the underlying weatherforecast model and the amount of observational data entering the assimilation system used to produce them (see example fields given in Dee et al., 2011, and we expand on this in Sect. 2.6). Many users of reanalysis products attempt to adjust them to observational distributions through a process that is referred to using different terminology: bias adjustment and calibration being the most commonly used terms (Maraun et al., 2010). Here, the term bias adjustment is used.

The principal reason for performing a bias adjustment is that reanalyses are potentially biased compared to direct station observations (even when the station observations are gridded to a comparable spatial resolution), more so for some variables than others (e.g. precipitation compared to temperature), and the bias may also vary in value, space, and time; i.e. the bias may be larger for more extreme values or it might be larger for regions or time periods of sparse station coverage. The importance of the bias depends to a large extent on how the data will be used. For some variables, the monthly average/totals will be important, but many other users require that extremes of the distribution be well simulated. With time, the complexity of approaches to bias adjustment has developed from getting the monthly averages correct to the present attempts to adjust the whole distribution and to even account for the multivariate relationships between some variables (see, e.g., Vrac and Friederichs, 2015). These advances reflect not only the greater expectations with each generation of reanalysis but also the greater number of users in a greater number of sectors.

A widely used bias-adjustment dataset was developed in the WATCH project (Weedon et al., 2010, 2011, 2014). The methodology applied to ERA-40 reanalysis data to create the WATCH Forcing Data (Weedon et al., 2010, 2011) was used later with ERA-Interim data to produce the WFDEI dataset (WATCH Forcing Data methodology applied to ERA-Interim data; Weedon et al., 2014). Bias adjustment in WFDEI was undertaken on the monthly average scale for a number of hydrological variables necessary to calculate evapotranspiration, soil moisture, and runoff (so including air temperature, rainfall, snowfall, long-wave and short-wave solar radiation, wind speed, specific humidity, and surface pressure) and for the period of analysis 1958-2001 (1979-2014) based on the ERA-40 (ERA-Interim) reanalysis. The dataset was developed for forcing land surface models using meteorological data (bias-adjusted reanalysis) and the WATCH project built on earlier work (Cosgrove et al., 2003; Sheffield et al., 2006), which also developed forcing datasets. The spatial coverage for WFDEI is all land areas north of latitude $60^{\circ} \mathrm{S}$. ECEM is less spatially extensive covering the European Domain (27- $72^{\circ} \mathrm{N}, 22^{\circ} \mathrm{W}-45^{\circ} \mathrm{E}$ ). The current period of study is 1979 2016 based on the ERA-Interim reanalysis with sub-daily and daily timescales.

The aim of this paper is to present the construction of a sub-daily bias-adjusted dataset of the climate variables listed above, by using ERA-Interim reanalysis. The ECEM dataset is freely available through the Climate Data Store (CDS) of C3S (currently ftp://ecem.climate.copernicus.eu). The benefit of performing bias adjustment is demonstrated by comparing initial and bias-adjusted data against station observations and gridded observation products. The ERA-Interim reanalysis and the gridded and station observation-based datasets used for bias adjustment are described in Sect. 2. Section 3 provides more information on the methods for bias adjustment on the daily and sub-daily timescales with a focus on the specific context of the energy sector. The selected techniques are discussed in Sect. 4. Section 5 discusses issues related to whether our bias adjustment is applicable to other sectors. Different sectors have different user demands relating to the variables required, timescales, and the length of historical reanalysis data needed. Section 6 gives details of dataset access.

\section{Data}

This section provides details of ERA-Interim and the various gridded and station observation datasets used to assess the quality of this reanalysis. With gridded datasets, the spatial resolutions may vary, so it is often necessary to regrid data onto a common resolution (in this study a grid of $0.5^{\circ} \times 0.5^{\circ}$ latitude $\times$ longitude).

\subsection{ERA-Interim}

The development of ERA-Interim is described by Dee et al. (2011). Surface air temperature, precipitation, wind speed at $10 \mathrm{~m}$, surface downwelling solar irradiance, and relative humidity data were extracted from ERA-Interim on its reduced Gaussian grid. The period is 1979-2016, and the temporal resolution is either $3 \mathrm{~h}$ (forecast) or $6 \mathrm{~h}$ (analysis), depending on the variable (see Dee et al., 2011, for details). These five are Essential Climate Variables (ECVs) defined by the Global Climate Observing System (Bojinski et al., 2014). After extraction, the variables have been regridded onto a latitude $\times$ longitude grid of $0.5^{\circ} \times 0.5^{\circ}$ for the ECEM domain using a bilinear interpolation technique. There are two principal reasons for this regridding: (i) some of the observation datasets for the assessment of ERA-Interim are available on this regular latitude $\times$ longitude grid (e.g. E-OBS; see next section), and (ii) potential users of the datasets developed here requested regular latitude $\times$ longitude grids with cells size of $0.5^{\circ}$ for practical reasons (in particular for aggregation to the country scale). It is also preferable to regrid a dataset without missing values, as opposed to an observation- 
based gridded product as these can contain missing values when some station data were not available.

\subsection{Gridded observation datasets}

Among the available gridded products for air temperature and precipitation, we used

- E-OBS for both variables (http://www.ecad.eu/, Haylock et al., 2008),

- CRU TS for both variables (CRU TS 3.23, https:// crudata.uea.ac.uk/cru/data/hrg/, Harris et al., 2014) and

- GPCC (Global Precipitation Climatology Centre) for precipitation (https://www.dwd.de/EN/ourservices/ gpcc/gpcc.html, Becker et al., 2013).

E-OBS, CRU TS, and GPCC data were downloaded for the ECEM grid. All three datasets only cover land regions, so any bias adjustment using these datasets will not include marine areas. E-OBS covers the period from 1951 to 2016, so fully encompassing the 1979-2016 period of ERA-Interim. CRU TS and GPCC cover the period from 1901 to 2016 (up to 2013 for GPCCv5) but are both monthly averages/totals, so can only provide an assessment on this timescale. These additional two monthly gridded datasets are included as they are used by the WATCH/WFDEI (Weedon et al., 2011, 2014) dataset, and we will compare our bias-adjusted ERA-Interim dataset with this dataset in Sect. 4.5.

\subsection{HadISD}

No gridded observed product is available for wind speed and dewpoint temperature. Dewpoint temperature is necessary as it can be combined with air temperature to calculate relative humidity, which is needed for energy calculations, such as demand. Station data for wind speed at $10 \mathrm{~m}$ height and dewpoint temperature were extracted from HadISD (http: //www.metoffice.gov.uk/hadobs/hadisd/) for approximately 1500 stations across Europe. Station data were extracted every $6 \mathrm{~h}$ at the SYNOP hours 00, 06, 12, and 18 for the period 1979-2014 (Smith et al., 2011; Dunn et al., 2012). We additionally extracted air temperature data from HadISD, so we could use this with the concurrent dewpoint temperatures to calculate dewpoint depression (see later in Sect. 4.2). HadISD has additionally been assessed for long-term homogeneity by Dunn et al. (2014). Variations in station coverage within HadISD are considerably greater than the coverage achieved for air temperature from E-OBS and precipitation from E-OBS and GPCC. This indicates that it would be unwise to attempt spatial interpolation to a $0.5^{\circ} \times 0.5^{\circ}$ grid using the HadISD stations. Instead each station series will be compared with that from the nearest ERA-Interim grid-box series.

\subsection{Surface solar irradiance from the World Radiation Data Center and the Baseline Surface Radiation Network}

National meteorological services (NMSs) usually measure surface solar irradiance at a limited number of sites. Data are sent to the World Radiation Data Center (WRDC), a laboratory of the Voeikov Main Geophysical Observatory in SaintPetersburg, Russia, under the control of the World Meteorological Organization (WMO). There, the data are archived and published (http://wrdc.mgo.rssi.ru). Most of the data are daily irradiation; hourly (or higher-frequency) irradiation is available at very few sites. All data are scrutinized at WRDC and quality-flagged before entering archives. Additionally, six stations were added from the Baseline Surface Radiation Network (BSRN, http://bsrn.awi.de/). Altogether, 55 stations with high-quality daily irradiation data were kept, for which mean daily irradiance was computed.

\subsection{HelioClim-3v5 (HC3v5)}

Boilley and Wald (2015) have shown the need to correct ERA-Interim estimates of solar irradiance. As only a limited number of stations are available for solar irradiance over Europe (but also globally), it was decided to exploit the satellite-derived HelioClim-3v5 (HC3v5) dataset to correct ERA-Interim. HC3v5 originates from the daily processing of images acquired by the series of satellites Meteosat-MSG by the Heliosat-2 method (Blanc et al., 2011; Rigollier et al., 2004). In version 5 of HelioClim-3, a correcting table was developed in 2015 between 15 min estimates made by HelioClim-3 and data from the six BSRN stations. It has been established by merging all data; i.e. it is a global correction and not a local one. Inputs to the correcting table are the solar zenith angle and the HelioClim-3 estimates; there is no local input. In this respect, $\mathrm{HC} 3 \mathrm{v} 5$ is independent of the surface station data in BSRN and also data from WRDC.

HC3v5 does not cover the northern part of the ECEM domain. The first estimates began on 1 February 2004, and these have been compared satisfactorily with measurements taken at ground stations (Eissa et al., 2015; Thomas et al., 2016a, b; Marchand et al., 2017). HC3v5 data were downloaded from the SoDa (Solar Radiation Data) Service website (www.soda-pro.com) from which one may select the timescale, here the daily mean of irradiance $I$. The HC3v5 product comprises the irradiance at the top of atmosphere $E_{0}$, from which one may compute the clearness index $K_{\mathrm{T}}$ :

$K_{\mathrm{T}}=I / E_{0}$.

$K_{\mathrm{T}}$ is a good indicator of the optical state of the atmosphere with a dependency on the position of the sun that is much less pronounced than in $I . K_{\mathrm{T}}$ greater than 0.7 signifies a clear sky, while $K_{\mathrm{T}}$ less than 0.2 signifies an overcast sky. The advantage of HC3v5 over the station series is that it provides gridded data for the ECEM domain up to $60^{\circ} \mathrm{N}$. The inde- 
pendent station data from WRDC and BSRN will be used in Sect. 4.4 for assessing the performance of the bias adjustment for solar irradiance.

\subsection{Independence of the station/gridded observation series versus ERA-Interim}

In this study, we propose bias-adjusting ERA-Interim for the five ECVs (wind speed, air temperature, dewpoint temperature, precipitation, and irradiance). As stated in Sect. 2.1, ERA-Interim assimilates many different climate datasets: surface station data are just one set of several; satellite and radiosonde data are also assimilated. In this section, we discuss how independent the station observations and gridded products are that are used in this bias adjustment compared to the surface station data assimilated into ERA-Interim. Precipitation and irradiance data are totally independent as these data are not assimilated. These variables are forecast outputs from ERA-Interim (see Dee et al., 2011). Of the other three variables, near-surface air and dewpoint temperatures are assimilated. For wind, the $u$ and $v$ components of the $10 \mathrm{~m}$ wind speeds are assimilated. It is important to understand what is assimilated and what importance may be given to these variables. The output for these three variables used is their value in the analysis (referred to as an analysis variable), produced every $6 \mathrm{~h}$.

ERA-Interim does not provide details of all the specific station data (and additional satellite and radiosonde data) that are assimilated. Dee et al. (2011) give details of what datasets are available for assimilation. ERA-Interim provides a dynamically consistent estimate of the climate state at each $6 \mathrm{~h}$ time step, but it does not specifically give any details of which potential information was used to produce the analysis variables. Through dynamical consistency, information from satellites, radiosondes, and other surface variables (e.g. pressure) are also used. Essentially, the quantity of surface station data for Europe is similar to that available in the HadISD database, which we know is about 1500 series, but only about 800 are relatively complete over the 1979-2014 period (Dunn et al., 2012, 2014). Thus, for air temperature, the $\sim 2000$ additional daily $T_{x}$ and $T_{n}$ observations are not assimilated. So our E-OBS dataset for air temperature contains a much greater volume of additional temperature series than assimilated within ERA-Interim. The wind speed and dewpoint temperature from HadISD should have been available for assimilation, but the importance given to these observations is not as great as the importance given to the station pressure observations.

The production of a reanalysis has occasionally been referred to as dynamic infilling, which is quite different from the statistical spatial infilling techniques that are used to produce the E-OBS, CRU TS, and GPCC datasets. Spatial infilling techniques use a variety of statistical procedures (e.g. inverse distance weighting and kriging) and are generally applied for each variable independently of other variables. In data-sparse regions, statistical-infilling techniques will likely spread information from the few available stations across the unobserved areas. The effects of this are generally evident as reduced variance in the generated fields. In contrast, a reanalysis will make use of additional information (e.g. the largescale circulation and satellite information), potentially not placing great emphasis on a specific observed variable (e.g. wind observations). In addition, balances of mass, wind, and energy fields mean that consistency between different variables is ensured, though this is particularly the case for forecast variables at a few to several hours lead time. At analysis time, such balances might be not guaranteed, but this depends on the specific data assimilation scheme used and whether the scheme enforces physical/dynamical balances.

\section{Bias-adjustment approaches}

Bias adjustment and bias correction are widely used terms for the assessment of climate model output (from both global and regional climate models, GCMs and RCMs; see, e.g., Maraun et al., 2010; Maraun, 2012) generally through comparison with station observational data. In this context, the biases compared to observations, are often much larger than differences with recent reanalysis products. There are a number of studies where GCMs and RCMs are bias adjusted against reanalyses, so the assumption is made there that reanalyses are a true representation of the real climate. This happens more in regions where observational datasets are sparse and/or hard to access (Oyerinde et al., 2017, use the MERRA reanalyses, Rienecker et al., 2011, for air temperature, when bias-adjusting RCM simulations for western Africa). Bias adjustment of reanalyses has been undertaken for a number of years, though. An extensive exercise was carried out by the WATCH project (http://www.eu-watch.org/, see Weedon et al., 2011, 2014). This used the CRU TS and GPCC datasets as the basis for adjusting ERA-40 and ERA-Interim, and the adjustments are based on average monthly differences treating each variable independently of each other, as we will do.

Numerous and more complex (than Weedon et al., 2014) methods for bias adjusting climate variables derived from climate models have been proposed. A number of review papers have been published (e.g. Maraun et al., 2010; Maraun, 2013; Vrac and Friedrichs, 2015). Among the various possibilities are the cumulative distribution function (CDF) transform method of Vrac et al. (2012), the distribution-based scaling (DBS) method of Yang et al. (2010), empirical quantile mapping (Themeß1 et al., 2011, 2012; Wilcke et al., 2013), and using the R package "qmap" used by MetNorway (Gudmundsson et al., 2012). Unlike the bias adjustment within the WATCH project, the latest examples from the literature attempt to address the issues of spatial dependence of the bias (any bias in ERA-Interim for a variable is expected to be relatively smooth) and temporal dependence (biases may 
be greater for certain types of weather, which has led to the approaches improving the fit between the distributions), and some attempt to adjust climate variables in a multivariate way (e.g. Vrac and Friedrichs, 2015).

Research in the literature has tended to emphasize precipitation (where bias adjustment can also be classed as a form of downscaling). In ECEM, precipitation is less important, with instead a greater emphasis on wind speed and solar irradiance as well as temperature. As stated earlier, how good bias adjustment has to be depends on how the adjusted data will be used. Within ECEM, techniques were selected to be fit for purpose, and that purpose is energy sector applications. Even though users in the energy sector are a diverse group, they are mainly interested in only one or two variables, and our initial determination of their needs indicated that univariate bias adjustment will be sufficient.

\section{Bias adjustment and results}

In the present work, the same univariate approach as Weedon et al. (2014) was followed, and ERA-Interim was compared against the gridded observational products on the monthly timescale. The bias was computed as the mean of the differences (model minus observations). For both temperature and precipitation (not shown), differences are generally greater (but variable in sign) over mountainous regions and some coastal areas (the Norwegian coast for temperature and most west-facing coasts for precipitation). Users in the energy sector are much more interested in the extremes of the distribution, so the approach moved to adjusting the whole ERAInterim distribution on the daily and sub-daily timescales, using a different statistical distribution for each variable. The following sections begin with wind speed, then move to air and dewpoint temperature, then precipitation, and finally a new approach entirely for solar radiation.

\subsection{Wind speed at $10 \mathrm{~m}$}

In this section, results from the univariate bias adjustment are presented starting with wind speed at $10 \mathrm{~m}$. For use in the energy sector, wind speeds at hub heights $(80-120 \mathrm{~m})$ are potentially more useful, but assessing ERA-Interim wind speeds from these heights is only possible at a limited number of masts (Harpham et al., 2016). Assessment over the whole domain is only possible using surface station measurements which measure wind speeds at $10 \mathrm{~m}$. The twoparameter Weibull distribution is the most-used probability distribution for representing wind speeds and is of strong relevance in the energy sector. The Weibull distribution, with scale parameter $\alpha>0$ and shape parameter $\beta>0$, has a cumulative distribution function for $x>0$ given by

$\operatorname{Pr}(X \leq x)=F(x ; \alpha, \beta)=1-\exp \left[-\left(\frac{x}{\alpha}\right)^{\beta}\right]$.
The scale parameter $\alpha$ relates to the mean wind speed, and $\beta$ characterizes the skewness of the distribution; typical values of $\beta$ range between 1 (highly variable wind speed) and 3 (fairly constant wind speed). The 2-parameter Weibull distribution was fitted to $6 \mathrm{~h}$ wind speed data from ERA-Interim on a monthly basis, i.e. a separate fit was made for each month of the year, for each grid box using all the $6 \mathrm{~h}$ data for 1981-2010, irrespective of the wind direction. The same approach was applied for the wind data from 803 stations in the HadISD dataset that have at least $66.6 \%$ data completeness for this 30-year period. The scale and shape parameters $(\alpha$, $\beta$ ) for the 803 stations were compared with the same parameters from the nearest ERA-Interim grid box. Figure 1 shows differences (ERA-Interim minus observations) between the scale and shape parameters for January across the European domain. The maps indicate generally good agreement for January, i.e. the values for the two parameters are generally within \pm 1 of each other. Exceptions may be found in some mountainous regions and around west-facing coasts but this is very dependent on the month (larger differences when wind speeds are stronger). The similarity of the two distributions in terms of their scale and shape parameters indicates that bias adjustment could be achieved by replacing the ERAInterim scale and shape parameters with those inferred from the HadISD stations.

Equation (3) of Tye et al. (2014) provides a means to adjust the original variable $X$ into a variable $X^{*}$ having scale and shape parameters $\alpha^{*}$ and $\beta^{*}$ by the following power-law transfer function:

$X^{*}=\alpha^{*}\left(\frac{X}{\alpha}\right)^{\beta / \beta^{*}}$.

Where stations are available, $\alpha^{*}$ and $\beta^{*}$ are those of the stations. The scale and shape parameters computed at stations were interpolated to each ERA-Interim grid box with the bilinear INTERP function within the R Akima software package. A bias-adjusted dataset of wind speeds for ERAInterim is obtained by applying Eq. (3). Figures 2 and 3 exhibit the smoothed distributions using the HadISD observations, original ERA-Interim, and bias-adjusted ERAInterim for the 12 calendar months for the stations Kirkwall, Scotland, and Maribor, Slovenia. These two locations were chosen as one is maritime and the other more continental. The other 801 distributional fits are shown on the ftp site with the unadjusted and adjusted ERA-Interim grids (ftp://ecem.climate.copernicus.eu). The smoothed representations of the distributions are curtailed below zero wind speed. It is clear from these two examples that the distributional fit for the stations has moved the adjusted ERA-Interim data series towards the observational distribution, more so for Kirkwall, which shows a much greater improvement than for Maribor, where the distribution moves are a clear improvement in winter months but less so for spring and early summer months. Bias adjustment is less successful than in the examples shown for a few stations located in coastal areas 

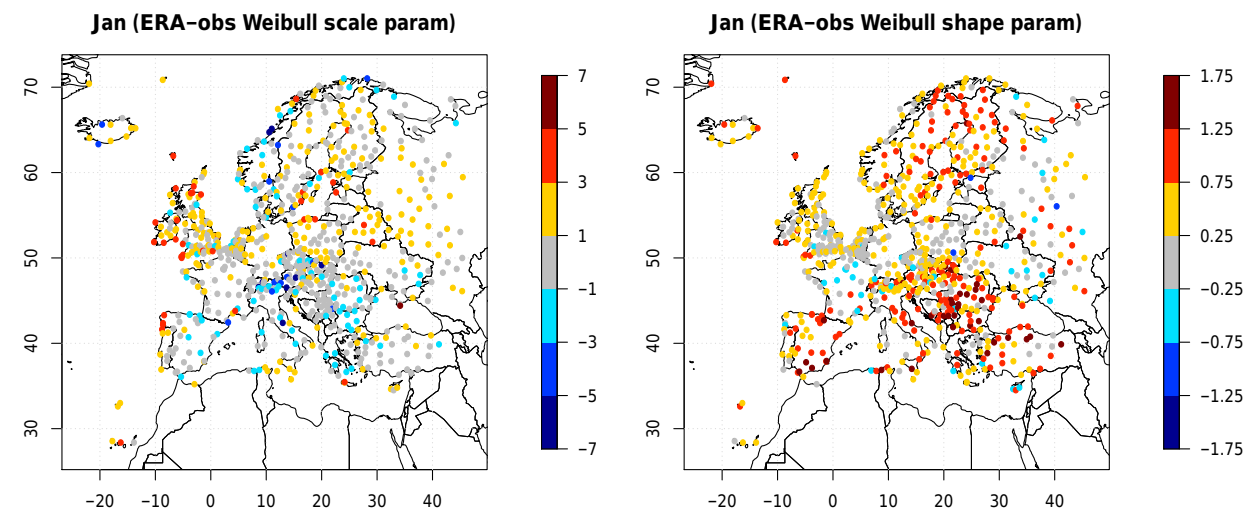

Figure 1. Differences in scale and shape parameters of the Weibull distribution between ERA-Interim and HadISD station observations for wind speed at $10 \mathrm{~m}$. Based on all 6-hourly data for January for 1981-2010.

and a few sites in mountainous regions (see the full set of distributional fits on the ftp site). Some observed distributions are a little erratic due to some years in the observed data having wind speeds rounded to integer values. Similarly to Fig. 1, but for bias-adjusted ERA-Interim minus observations, Fig. 4 shows differences between the scale and shape parameters for January. Almost all stations across Europe exhibit similar shape and scale parameters between the stations and adjusted ERA-Interim. However, a few stations in coastal areas and at high-elevation mountain locations still show differences in parameters. The fit is not perfect as the estimation of the shape and scale parameters for the ERA-Interim grid boxes from HadISD is influenced by the station distribution. In addition, the number of stations in some parts of Europe is less dense and so involves greater extrapolation from stations more distant from the grid boxes.

\subsection{Surface air temperature, dewpoint temperature, and relative humidity}

Like wind speed, both surface air temperature and dewpoint temperature are produced from ERA-Interim every $6 \mathrm{~h}$. Unlike $10 \mathrm{~m}$ wind, both these variables have a strong diurnal cycle, which is generally slightly stronger in the summer. A normal distribution was fitted using daily averages of temperature, taking the average of the four $6 \mathrm{~h}$ data for each day. E-OBS is the dataset on which ERA-Interim is to be adjusted for air temperature. For dewpoint we use HadISD, but we combine this with air temperatures from HadISD to calculate dewpoint depression (DPD), the difference between air and dewpoint temperature. To calculate DPD, we need to pair off air and dewpoint temperature measurements taken every $6 \mathrm{~h}$. DPD will always be $\geq 0$, so we use a Weibull distribution to ensure that any bias adjustments always produce a DPD that is $\geq 0$. Means and standard deviations of the daily average of air temperature are calculated for each month of the year for each $0.5^{\circ}$ grid cell of ERA-Interim coincident with the E-OBS grid box. The distributional parameters for DPD are interpolated as for wind speed; then, based on air temperature, a dewpoint temperature can be calculated. Data are normalized as in Eq. (4) and transformed back by Eq. (5) for air temperature.

$T_{\mathrm{ERA}}^{\prime}=\frac{T_{\mathrm{ERA}}-\bar{T}_{\mathrm{ERA}}}{\sigma_{\mathrm{ERA}}}$,
$T^{*}=T_{\mathrm{ERA}}^{\prime} \sigma_{\mathrm{obs}}+\bar{T}_{\mathrm{obs}}$,

where $T^{\prime}$ is the normalized ERA-Interim temperature anomaly, $T^{*}$ is the bias-adjusted ERA-Interim temperature, $\bar{T}$ is the mean temperature, and $\sigma$ is the standard deviation. Bias adjustment works by transforming the normalized ERAInterim grid-box time series back to air temperatures using the means and standard deviations from E-OBS and interpolations from station data in HadISD for DPD. Once daily averages are adjusted, the difference between the original ERAInterim daily mean and the adjusted daily mean is added to each of the four $6 \mathrm{~h}$ temperatures within each day. Therefore, no alteration is made to each diurnal cycle of air temperature or DPD. This yields the final set of bias-adjusted $6 \mathrm{~h}$ surface air and dewpoint temperatures (the latter calculated from DPD) consistent with one another.

Figure 5 shows the differences in the mean and standard deviation for air temperature for April as an example. There is good agreement between estimates for ERA-Interim and those calculated from E-OBS. As these are both gridded datasets, the maps shown are fully coloured for each $0.5^{\circ}$ grid box. Differences in Fig. 5 are likely related to elevational differences in the $0.5^{\circ}$ grid boxes between E-OBS and ERA-Interim. The significance of this is discussed more in Sect. 4.5 when our adjusted ERA-Interim and the WFDEI datasets are separately compared with E-OBS. Figures 6 and 7 exhibit the distributional fits of the E-OBS, original ERA-Interim, and bias-adjusted ERA-Interim for the 12 calendar months for the nearest land grid boxes that approximate the locations of Kirkwall and Maribor used for wind speed. For Maribor, this is the $0.5^{\circ}$ grid box where the city 
adjERA and ERA-Interim 6 hourly $10 \mathrm{~m}$ wind speed vs. Kirkwall Airport (UK, 59.0, -2.9) obs
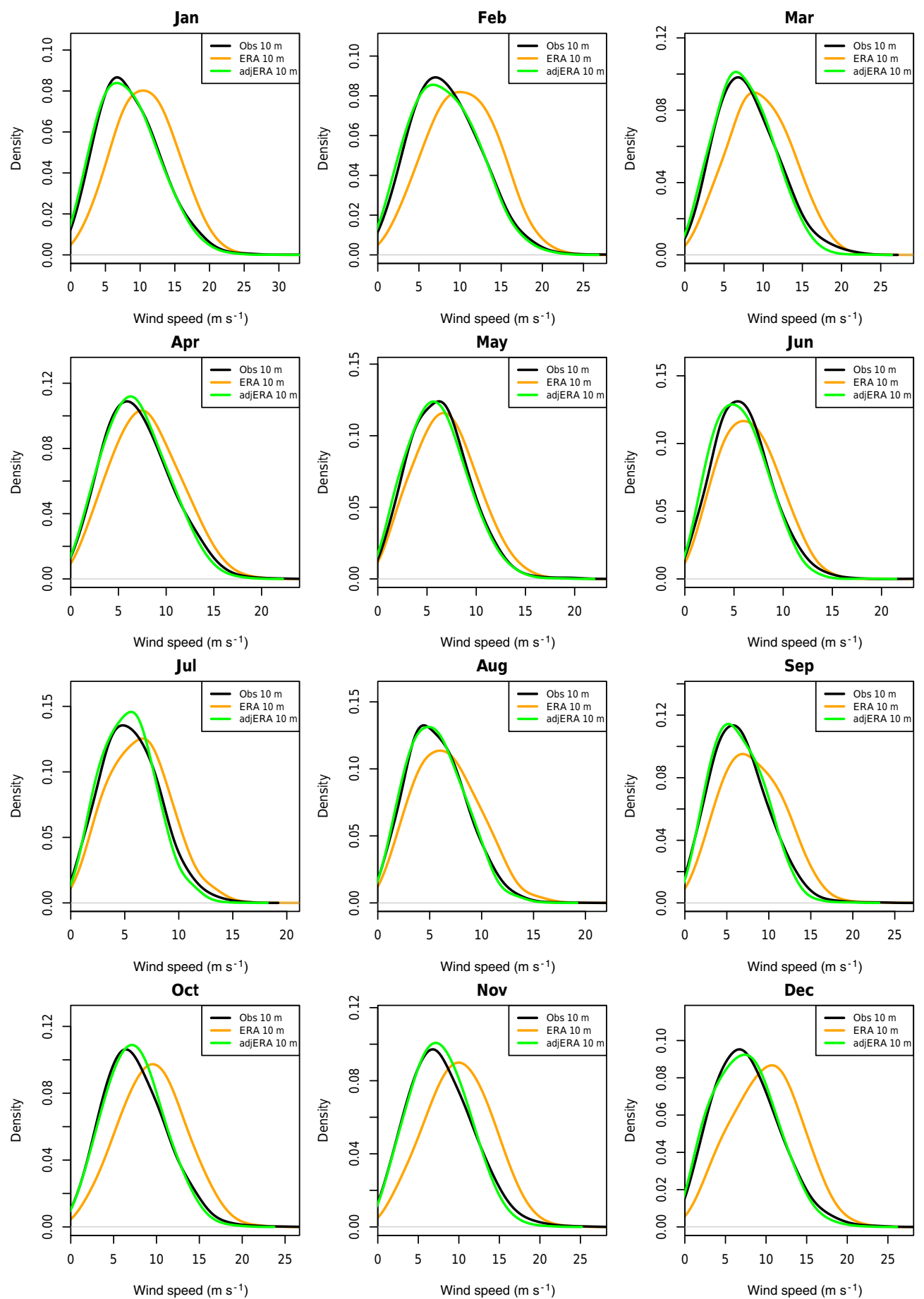

Figure 2. Comparison of statistical distributions of wind speed at $10 \mathrm{~m}$ for Kirkwall, Scotland, for observations (black), ERA-Interim (orange), and bias-adjusted ERA-Interim (green), based on all 6-hourly data for the 1981-2010 period.

is located. Kirkwall is on the Orkney Islands, so the nearest grid box within E-OBS is located further south in northern Scotland. The distributional fits for the Maribor grid box were good for ERA-Interim, and bias adjustment brings mi- nor improvement. For the Kirkwall grid box, the adjustments improve the fits in all months but are less good for the cold tail of air temperature in winter. The full set of results for the 4621 grid-box comparisons can be viewed on the ftp site. The 

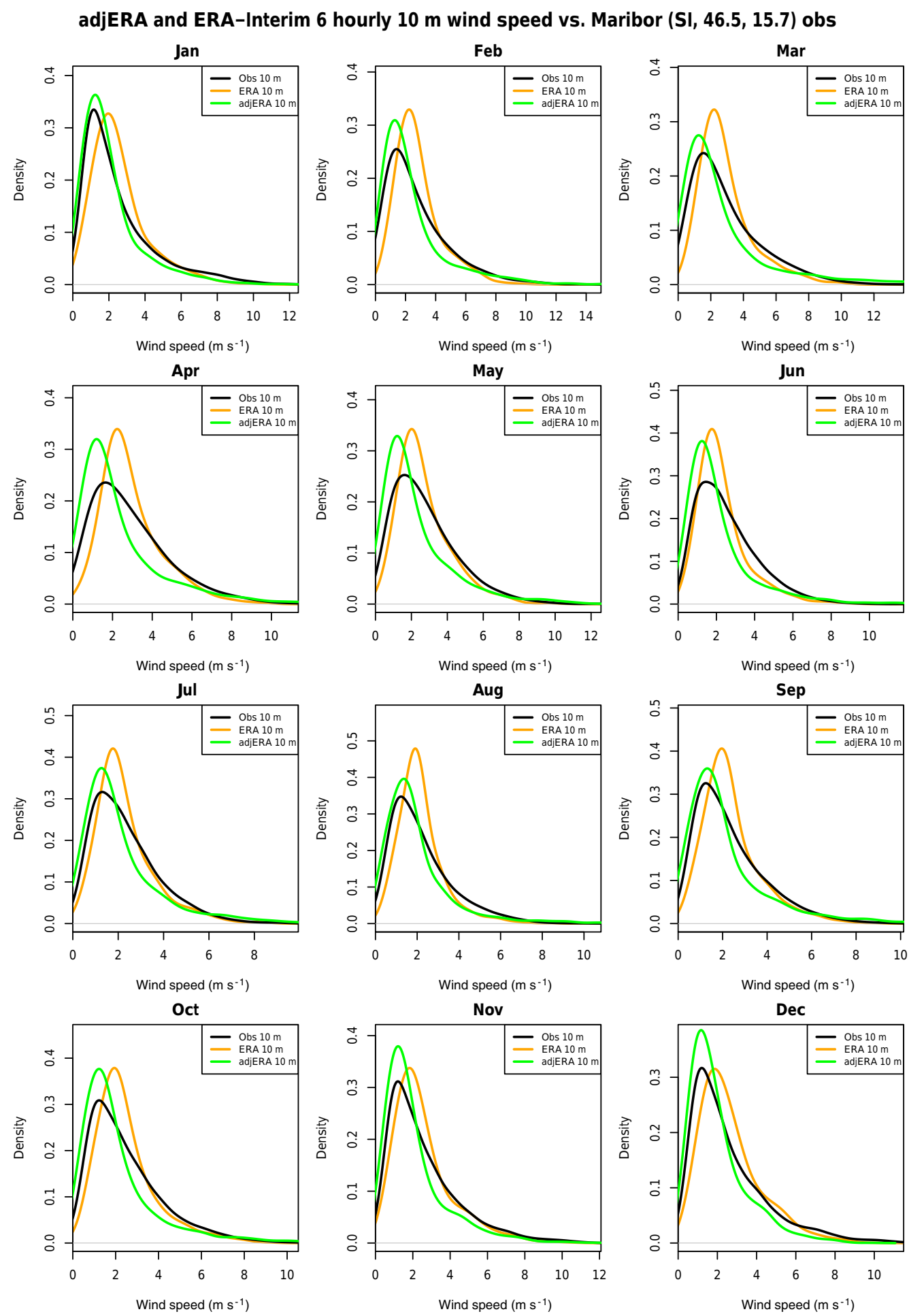

Figure 3. Comparison of statistical distributions of wind speed at $10 \mathrm{~m}$ for Maribor, Slovenia, for observations (black), ERA-Interim (orange), and bias-adjusted ERA-Interim (green), based on all 6-hourly data for the 1981-2010 period.

Kirkwall example and also most of the northern and eastern Europe comparisons illustrate an issue with approximating daily air temperature by a normal distribution for winter. For these regions (see the full set of results), daily winter air temperatures are often negatively skewed. This is even apparent in monthly temperatures but is more clearly visible on the 

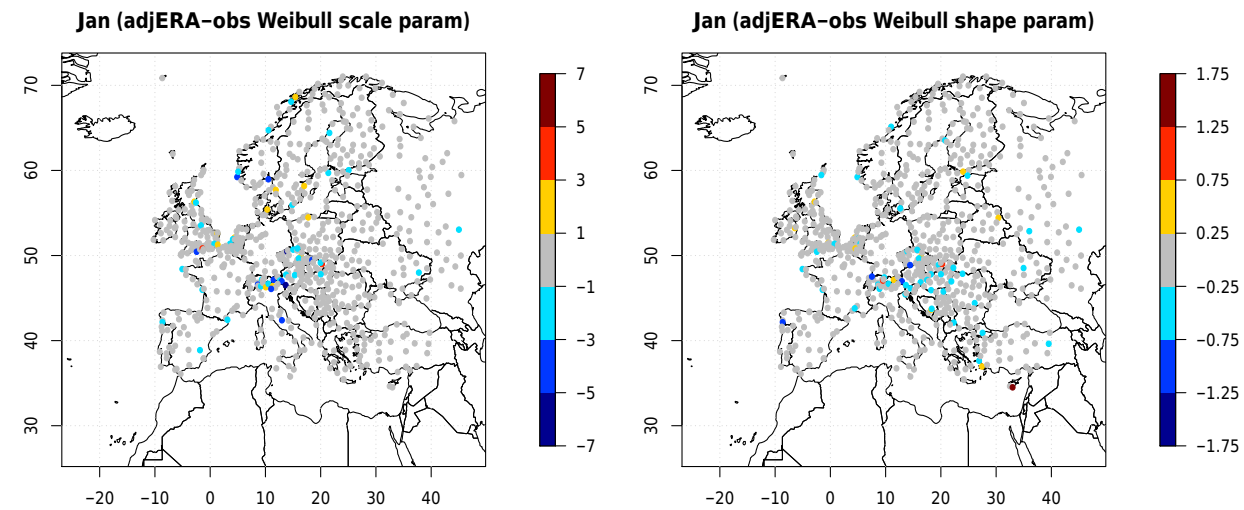

Figure 4. Differences in scale and shape parameters of the Weibull distribution between bias-adjusted ERA-Interim and HadISD station observations for wind speed at $10 \mathrm{~m}$. Based on all 6-hourly data for January for 1981-2010.
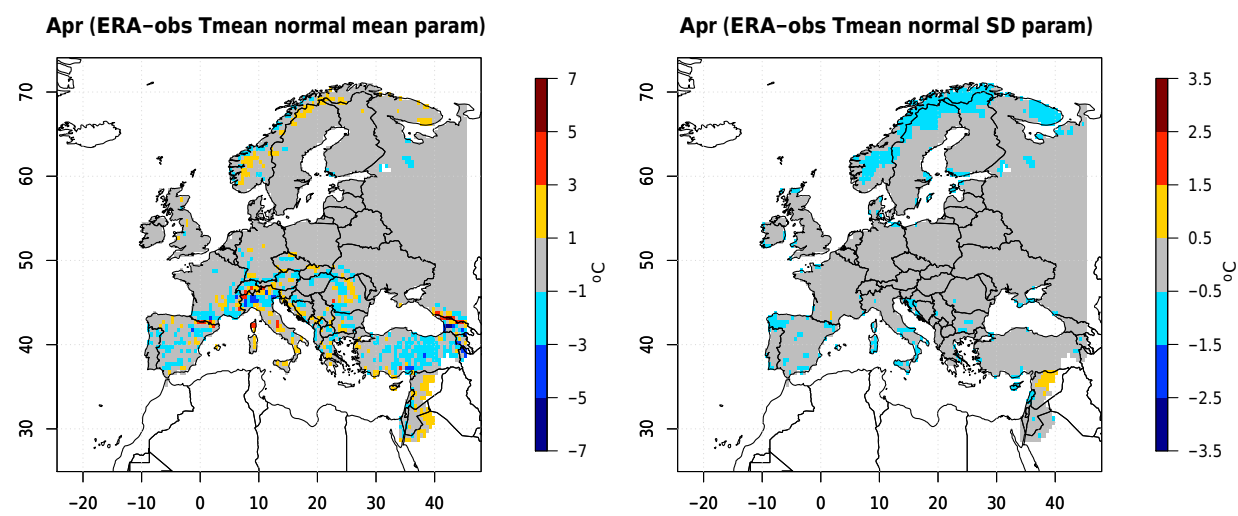

Figure 5. Differences in means and standard deviations (SDs) between ERA-Interim and E-OBS for mean surface air temperature (Tmean). Based on daily data for April for 1981-2010.

daily timescale. Horton et al. (2001) experimented with an alternate distribution (an inverted gamma distribution), but this adds an additional parameter to any bias-adjustment approach and fitting requires an interactive procedure. Figure 8 shows the differences between the means and standard deviations, but this time after adjustment, to allow comparison with Fig. 5.

Figure 9 shows the differences in the Weibull distribution parameter plots for DPD for July. There is good agreement between estimates from ERA-Interim and those calculated from HadISD using DPD. This plot shows the station locations in a similar fashion to that for wind speed in Fig. 1. Figures 10 and 11 show the distributional fits of the HadISD, original ERA-Interim, and bias-adjusted ERAInterim for DPD for the 12 calendar months for the locations of Kirkwall and Maribor. Both examples of distributional plots adjust ERA-Interim slightly, but the original fits were quite good to start with. As with wind speed, the DPD distributions are curtailed for values $<0$. Similarly to Fig. 9, Fig. 12 shows the differences between the Weibull distribution parameters for DPD but after adjustment.
With the adjustments for dewpoint temperature using DPD, it is a simple task to then calculate relative humidity $(\mathrm{RH})$ using the adjusted air temperature. Performing the bias adjustment this way, we are assured that all $\mathrm{RH}$ values are between 0 and $100 \%$.

\subsection{Daily precipitation totals}

The same process was then used for daily precipitation totals but using a gamma distribution, which has been found to perform well in many studies (e.g. Wilks, 1995).

$F(x ; \alpha, \beta)=\left(\frac{x}{\beta}\right)^{\alpha-1} \frac{\exp \left(-\frac{x}{\beta}\right)}{\beta \Gamma(\alpha)}$

Gamma distributions have two parameters, shape $(\alpha)$ and scale $(\beta)$, and were fit to the daily precipitation totals for each month for ERA-Interim and for E-OBS. In Eq. (6), we show the probability density function where $\Gamma$ is the gamma function. Approaches to bias adjustment of precipitation have been extensively discussed (see, for example, Piani et al., 2010a, b). Several experiments were made ignor- 
ERA-Interim daily $2 \mathrm{~m}$ Tmean (unadjusted and adjusted) vs. E-OBS $(58.25,-3.75)$ obs
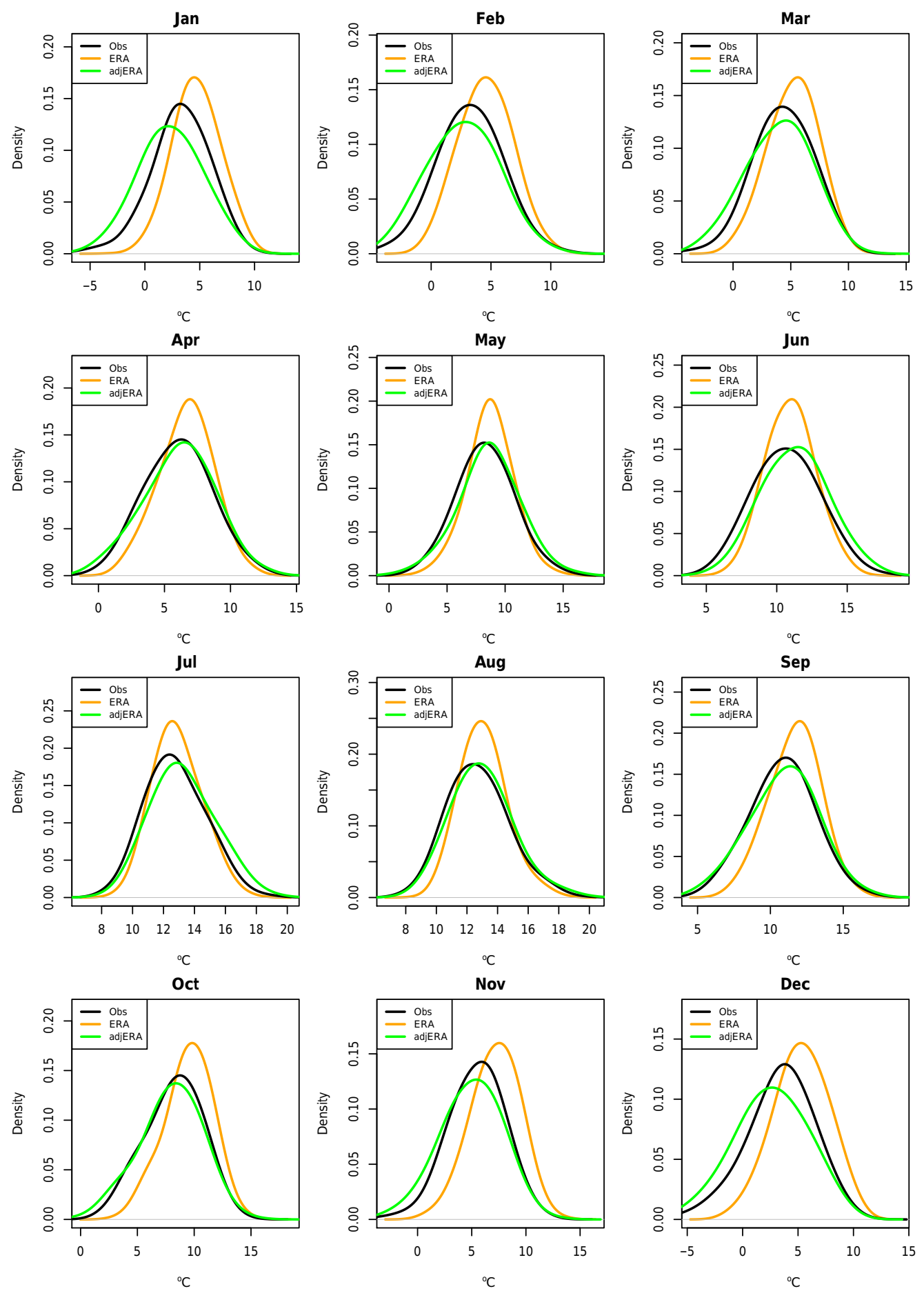

Figure 6. Comparison of statistical distributions of surface air temperature for northern Scotland $\left(58.25^{\circ} \mathrm{N}, 3.75^{\circ} \mathrm{W}\right)$, for observations (black), ERA-Interim (orange), and bias-adjusted ERA-Interim (green), based on daily data for the 1981-2010 period.

ing all precipitation values below a fixed low daily precipitation threshold over the whole domain. Thresholds of $0.4,0.6$, 0.8 , and $1.0 \mathrm{~mm}$ were experimented with and best fits were achieved with $1.0 \mathrm{~mm}$. This implies that the gamma distribu- tional fits are based only on days with precipitation values greater than the threshold, with a different fit for each month. This threshold ignores small precipitation totals, more so for ERA-Interim than for E-OBS but, as both datasets are in 
ERA-Interim daily $2 \mathrm{~m}$ Tmean (unadjusted and adjusted) vs. E-OBS $(46.25,15.75)$ obs
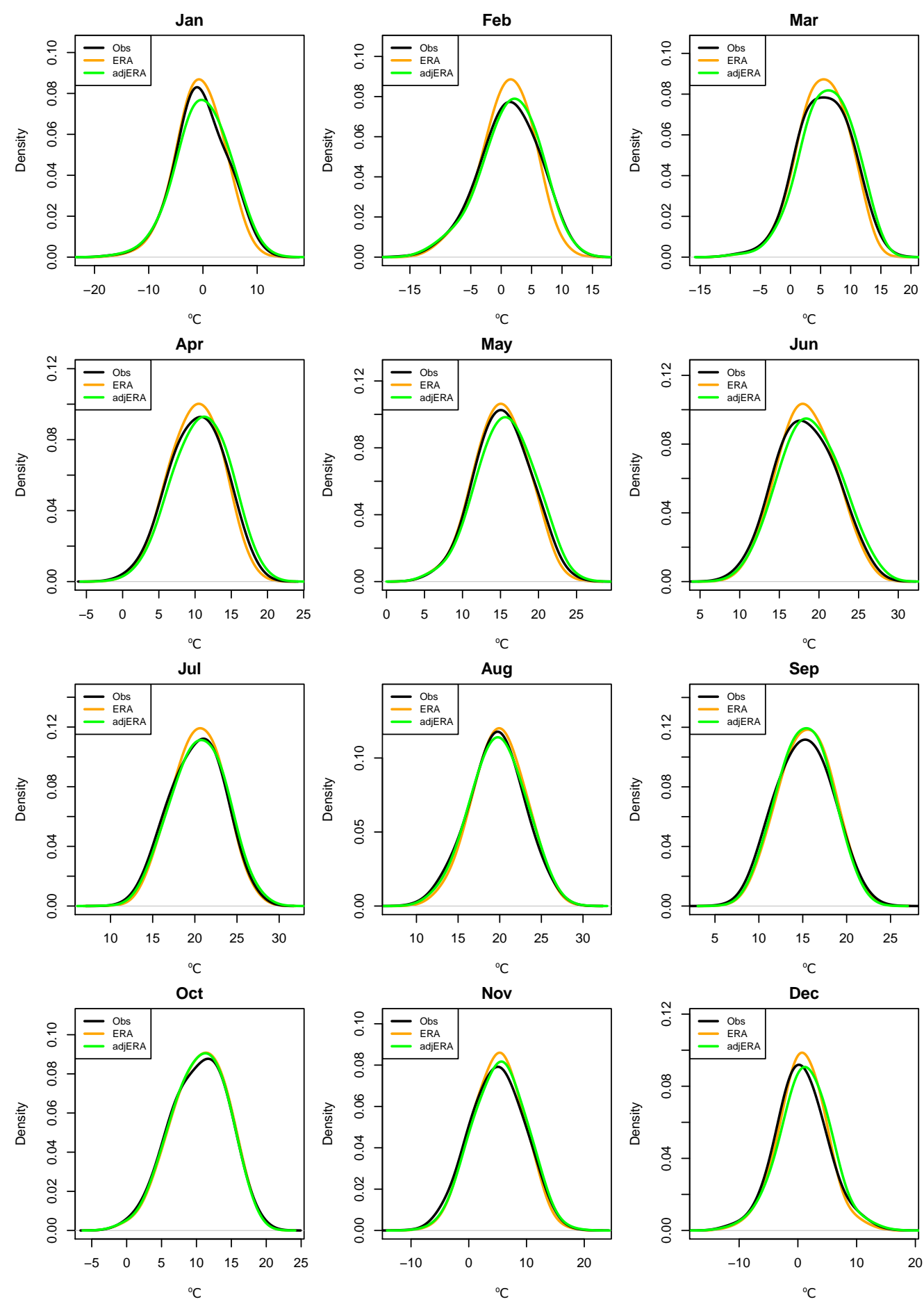

Figure 7. Comparison of statistical distributions of surface air temperature for the Maribor grid box $\left(46.25^{\circ} \mathrm{N}, 15.75^{\circ} \mathrm{E}\right)$, for observations (black), ERA-Interim (orange), and bias-adjusted ERA-Interim (green), based on daily data for the 1981-2010 period.

essence areal averages, more than would be the case for a station rain gauge series. In the adjusted ERA-Interim all precipitation amounts below the threshold are set to zero, further improving the agreement between E-OBS and ERA-Interim in the number of dry days per month (i.e. days with rainfall less than the $1.0 \mathrm{~mm}$ threshold). Adjustment is performed in a similar way to the temperatures, by back-transforming the 

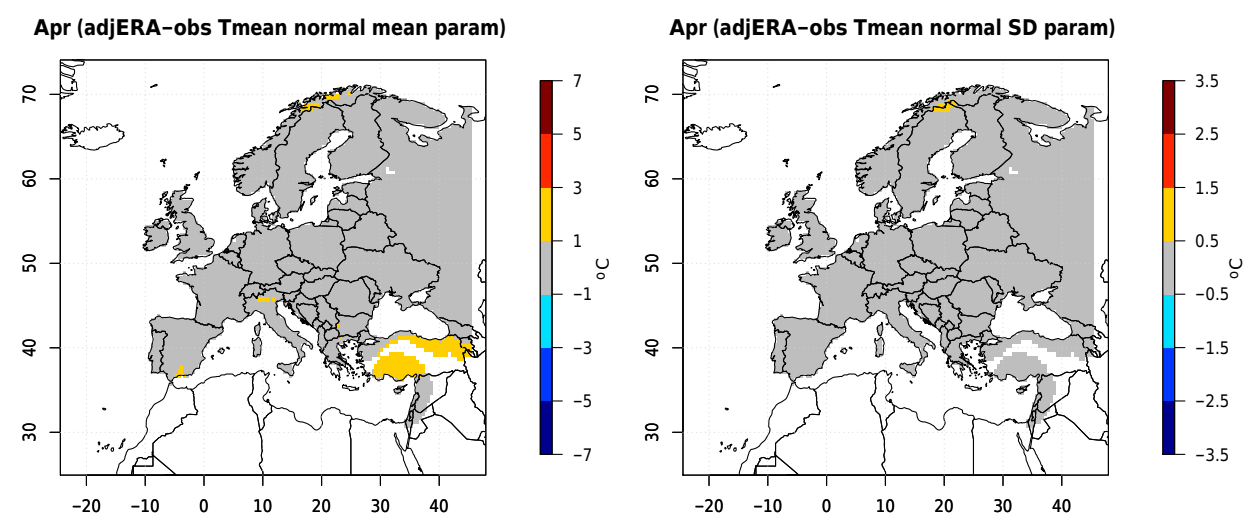

Figure 8. Differences in means and standard deviations (SDs) between bias-adjusted ERA-Interim and E-OBS for mean surface air temperature (Tmean). Based on all data for April for 1981-2010.
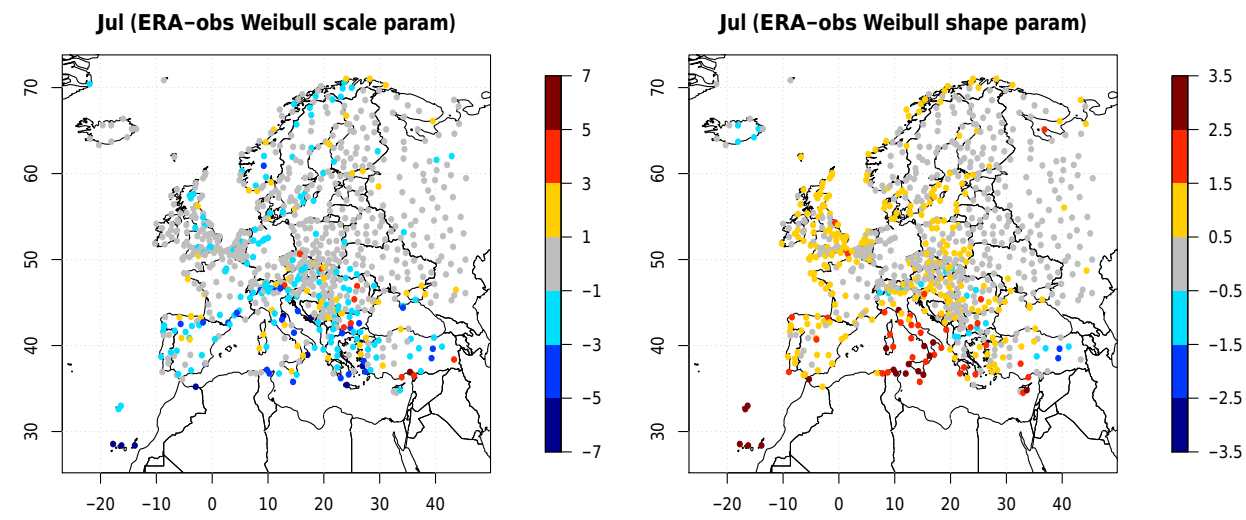

Figure 9. Differences in means and standard deviations (SDs) between ERA-Interim and HadISD for dewpoint temperature $\left({ }^{\circ} \mathrm{C}\right)$. Based on daily data for July for 1981-2010.

transformed ERA-Interim precipitation total with the scale and shape parameters from the E-OBS dataset.

Figure 13 shows the differences in the scale and shape parameters of the gamma distribution for October, by way of example. There is good agreement between estimates for ERA-Interim and those calculated from E-OBS. As these are both gridded datasets, the maps shown are fully coloured for each $0.5^{\circ}$ grid box. Of the 4520 possibilities, Figs. 14 and 15 exhibit the distributional fits of the E-OBS, original ERAInterim, and bias-adjusted ERA-Interim datasets for the 12 calendar months for the nearest land grid boxes that approximate the locations of Kirkwall and Maribor. The fits for the northern Scotland grid box are considerably better than for Maribor, where the distributional fits are slightly worse for April-August. Here only two locations are shown as examples: the full set of results for the 4520 grid-box comparisons can be viewed at the ftp site. The complete set uses common scaling, which may be inappropriate in drier parts of Europe and the fits (shown in the two examples in Figs. 14 and 15 are smoothed representations of the distributions curtailed at zero rainfall). Although the gamma distribution is widely used for rainfall data, it is not ideal in all climates and across all seasons in Europe. Problems arise when there are too few rainfall days within dry seasons (the southern Mediterranean and the Middle East during summer). Similarly to Fig. 13, Fig. 16 shows the differences between the scale and shape parameters after adjustment.

\subsection{Surface solar irradiance}

For the sake of simplicity, the adjustment was performed on the daily mean of irradiance. Three methods have been investigated: ratio, affine, and quantile mapping. Each method may be applied to the clearness indices $K_{\mathrm{t}}$ as well. The possible improvement in bias delivered by each method was assessed by comparing the original ERA-Interim estimates and the bias-adjusted ERA-Interim with measurements from the 55 WRDC stations. The method "ratio" consists of computing the means of HC3v5 $\overline{\mathrm{I}_{\mathrm{HC} 3 \mathrm{v} 5}}$ and ERA-Interim $\overline{\mathrm{I}_{\mathrm{ERA}}}$ for the calibration period of 2005-2014, then computing the ratio of these means $\left(\overline{\mathrm{I}_{\mathrm{HC} 3 \mathrm{v} 5}} / \overline{\mathrm{I}_{\mathrm{ERA}}}\right)$, and eventually multiplying the ERA-Interim estimates by this ratio for the entire period. The method "affine" consists in adjusting an affine func- 
adjERA and ERA-Interim daily 2 m DPD vs. Kirkwall Airport (UK, 59.0, -2.9) obs
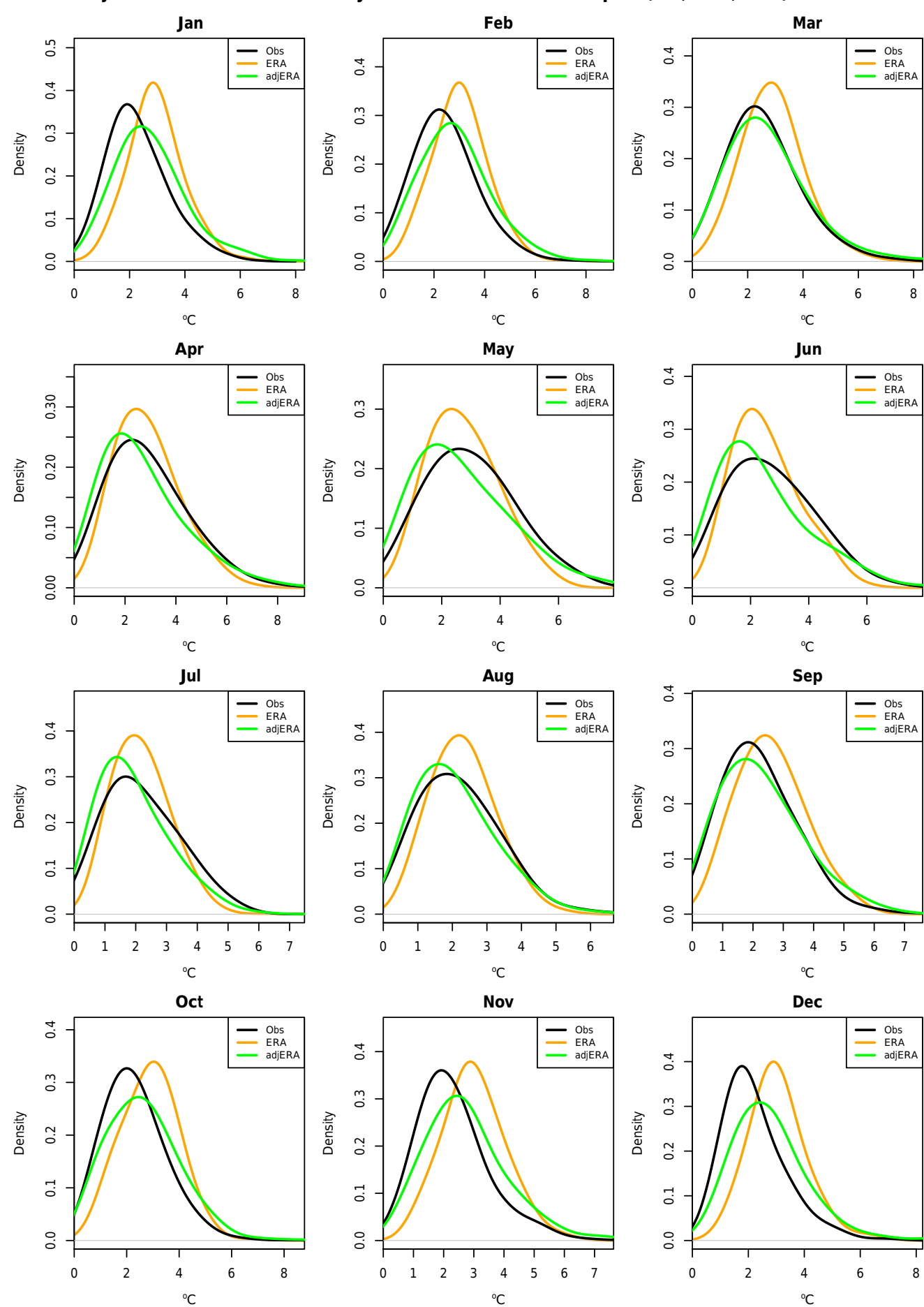

Figure 10. Comparison of statistical distributions of DPD for Kirkwall, for HadISD observations (black), ERA-Interim (orange), and biasadjusted ERA-Interim (green), based on daily data for the 1981-2010 period.

tion between HC3v5 and ERA for the calibration period and then applying this function to the ERA-Interim estimates. The method "quantile mapping" was used here (applied to the clearness index) and consists of adjusting the cumulative distribution function of ERA-Interim to that of HC3v5 for the calibration period, thus yielding an abacus that is used to convert the ERA-Interim estimates into adjusted irradiances. 

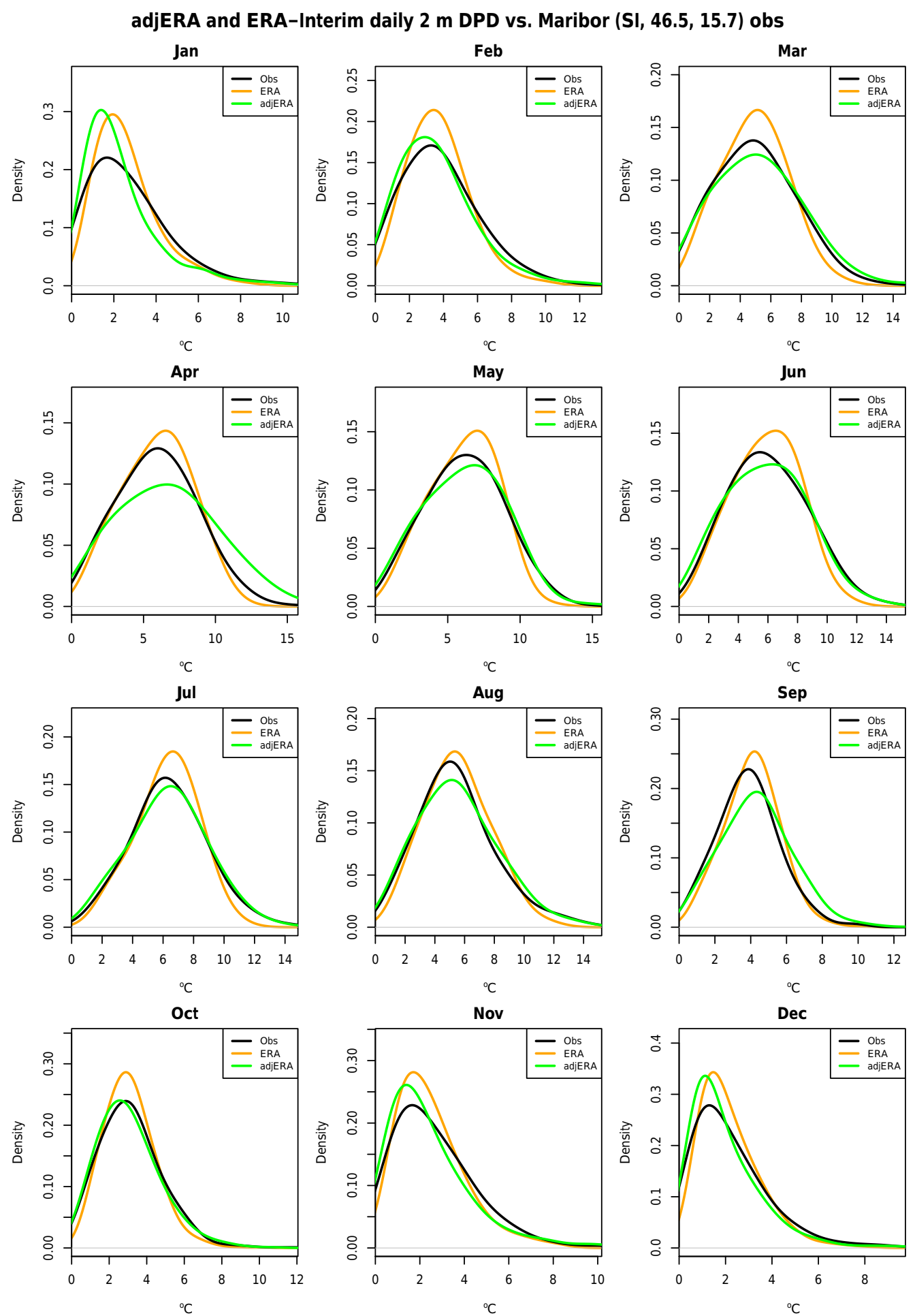

Figure 11. Comparison of statistical distributions of DPD for Maribor, for HadISD observations (black), ERA-Interim (orange), and biasadjusted ERA-Interim (green), based on daily data for the 1981-2010 period.

Figure 17 exhibits the bias for ERA-Interim vs. ground observations of daily mean of solar irradiance for the 55 stations. Downward triangles mean a negative bias of more than
$-5 \mathrm{~W} \mathrm{~m}^{-2}$, upward triangles mean a positive bias greater than $5 \mathrm{~W} \mathrm{~m}^{-2}$, and circles mean an absolute value of the bias less than $5 \mathrm{~W} \mathrm{~m}^{-2}$. The size of the triangles increases with 

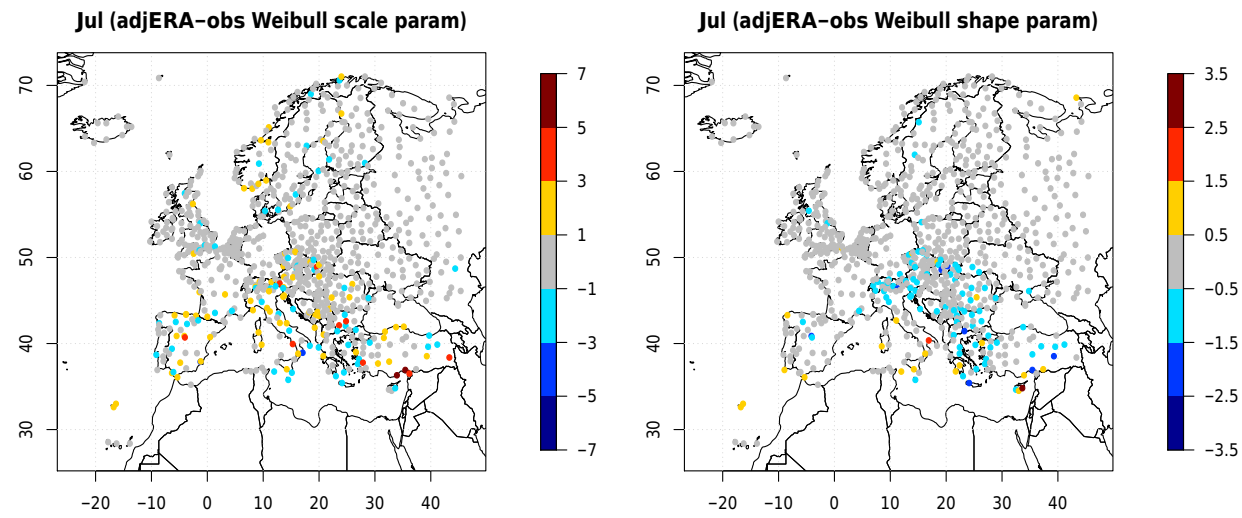

Figure 12. Differences in means and standard deviations (SDs) between bias-adjusted ERA-Interim and HadISD for dewpoint temperature $\left({ }^{\circ} \mathrm{C}\right)$. Based on daily data for July for 1981-2010.

Oct (ERA-obs precip gamma scale param)

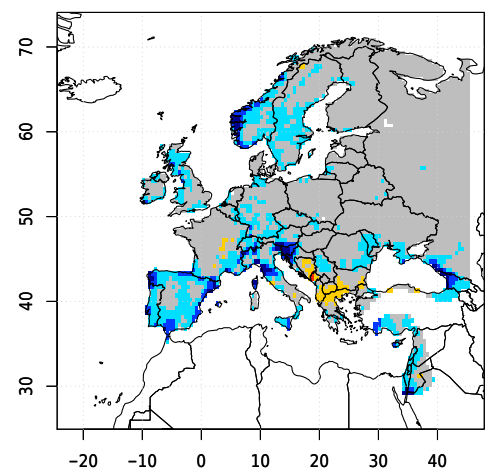

Oct (ERA-obs precip gamma shape param)

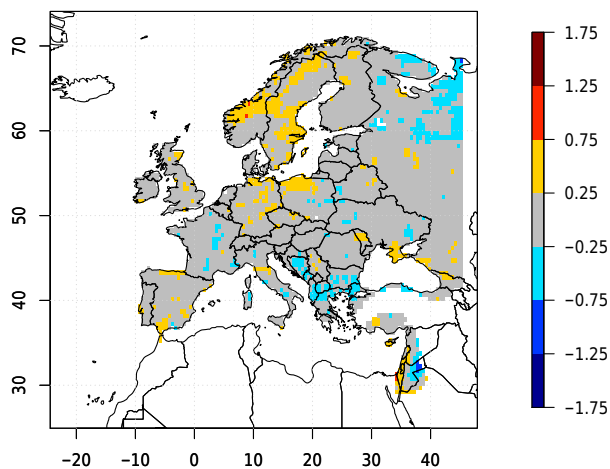

Figure 13. Differences in scale and shape parameters of the gamma distribution between ERA-Interim and E-OBS for precipitation daily totals $>1 \mathrm{~mm}$. Based on daily precipitation totals for October for 1981-2010.

increasing absolute value of the bias. Bias is often positive: i.e. ERA-Interim tends to overestimate the surface solar irradiance. Only 12 stations out of 55 exhibit an absolute bias of less than $5 \mathrm{~W} \mathrm{~m}^{-2}$.

HC3v5 does not cover latitudes north of $60^{\circ} \mathrm{N}$. Two stations, Lerwick (Scotland) and Borlange (Sweden), are located along this latitude (Fig. 17). No adjustment is performed to the grid boxes which are outside the coverage of HC3v5, except for the grid cells along the border where the new irradiance values are set to the mean of the original and adjusted irradiances to avoid spatial discontinuities. Figure 18 exhibits the improvement of bias after bias adjustment for surface solar irradiance for the 55 sites. Absolute values of the bias after adjustment are coded in three colours: blue for absolute value $<5 \mathrm{~W} \mathrm{~m}^{-2}$, yellow for $5<$ value $<10 \mathrm{~W} \mathrm{~m}^{-2}$, and red for value $>10 \mathrm{~W} \mathrm{~m}^{-2}$. Change in bias is coded by symbols: a circle for changes in an absolute value less than $5 \mathrm{~W} \mathrm{~m}^{-2}$, a downward triangle for improvement in bias, and an upward triangle for degradation. The size of the triangles increases with the improvement in bias. For example, a green downward triangle means that the bias has been decreased (downward triangle, i.e. improvement) and that after bias adjustment, the absolute value of the bias is less than $5 \mathrm{~W} \mathrm{~m}^{-2}$. One may see that there is an improvement or status quo for all stations; i.e. there is no upward triangle, only circles and downward triangles. In total, 22 stations out of 55 exhibit a bias less than $5 \mathrm{~W} \mathrm{~m}^{-2}$ in their absolute values, which is a strong improvement compared to the 12 for the original ERA-Interim data.

Once daily means are adjusted, the ratio between the original ERA daily mean and the adjusted daily mean is applied to each of the eight $3 \mathrm{~h}$ irradiances within each day. Therefore, no alteration is made to the diurnal cycle of irradiance. This yields the final set of bias-adjusted $3 \mathrm{~h}$ surface solar irradiance.

\subsection{Comparison of adjusted-ERA and WFDEl averages against E-OBS monthly averages for the 1979-2014 period}

In this section we plot differences for air temperature averages and precipitation totals for the four mid-season months (January, April, July, and October) between our adjusted 
ERA-Interim daily Ptotal (unadjusted and adjusted) vs. E-OBS $(58.25,-3.75)$
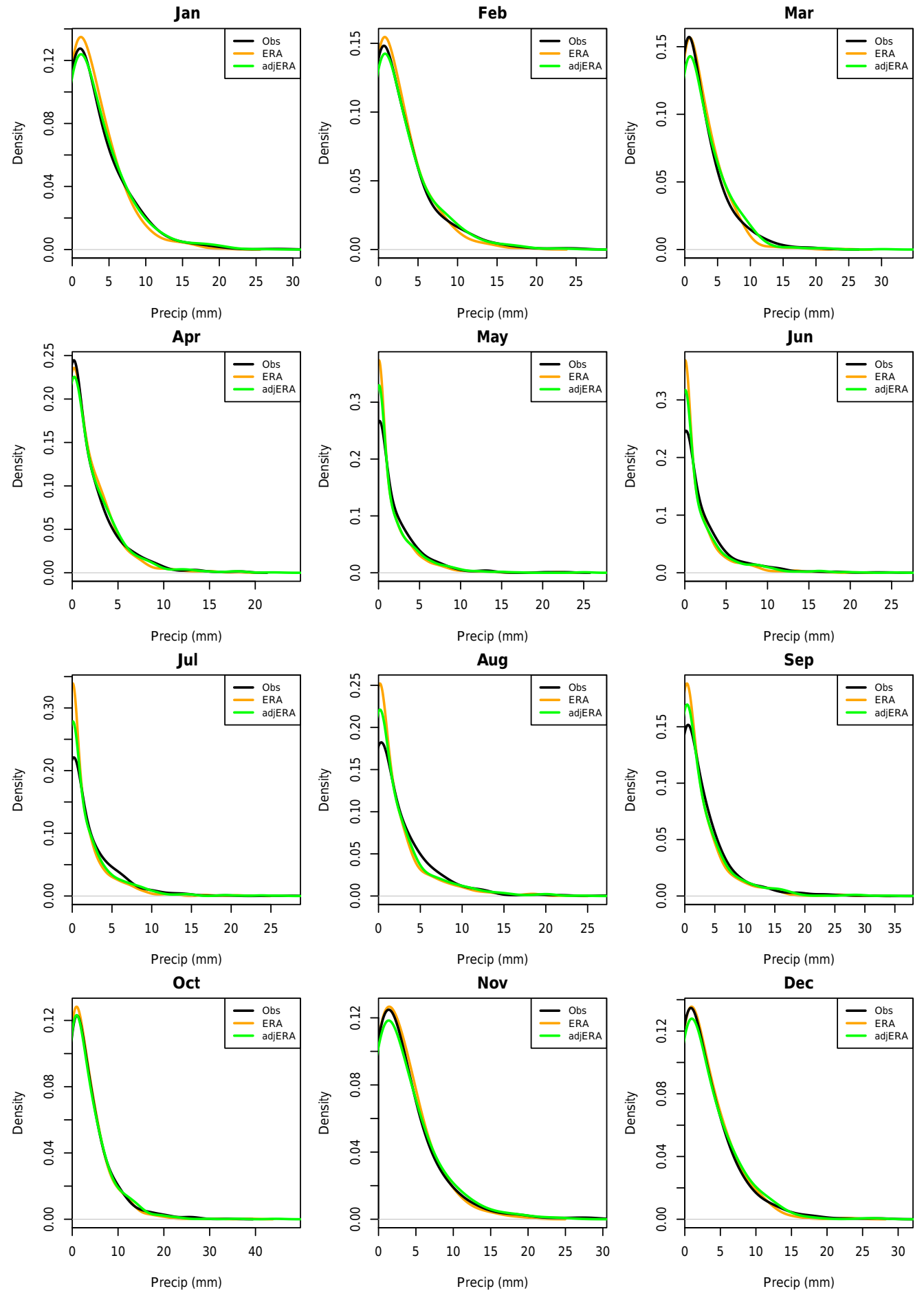

Figure 14. Comparison of statistical distributions of daily precipitation totals for northern Scotland $\left(58.25^{\circ} \mathrm{N}, 3.75^{\circ} \mathrm{W}\right)$, for observations (black), ERA-Interim (orange), and bias-adjusted ERA-Interim (green), based on the 1981-2010 period.

ERA-Interim data compared with E-OBS values for 19792014. Additionally, we plot differences between WFDEI and E-OBS for the same 36-year average. Figures 19-22 show the air temperature difference maps with Figs. 23-26 showing the differences for precipitation totals. Each figure contains two panels, first the adjusted ERA-Interim minus E- 
ERA-Interim daily Ptotal (unadjusted and adjusted) vs. E-OBS $(46.25,15.75)$
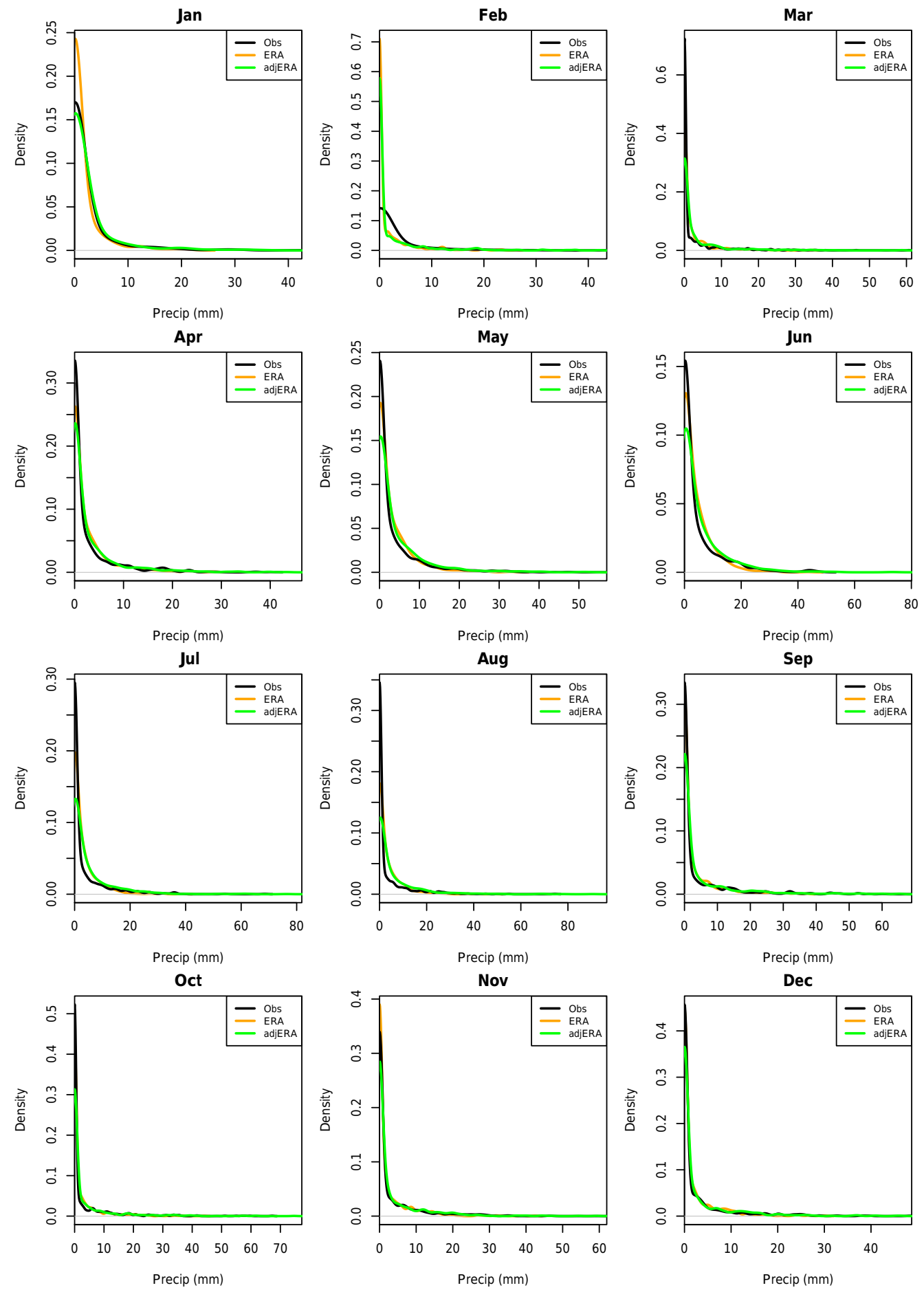

Figure 15. Comparison of statistical distributions of daily precipitation totals for the Maribor grid box $\left(46.25^{\circ} \mathrm{N}, 15.75^{\circ} \mathrm{E}\right)$, for observations (black), ERA-Interim (orange), and bias-adjusted ERA-Interim (green), based on the 1981-2010 period.

OBS and the second WFDEI minus E-OBS. All 12 monthly difference maps are available at the ftp site, with details given in Sect. 6. We have used E-OBS in our bias-adjustment pro- cedure, so this ought to portray our results in a favourable light with respect to WFDEI. Our reason for this is that E-OBS uses many more station series than other possible 

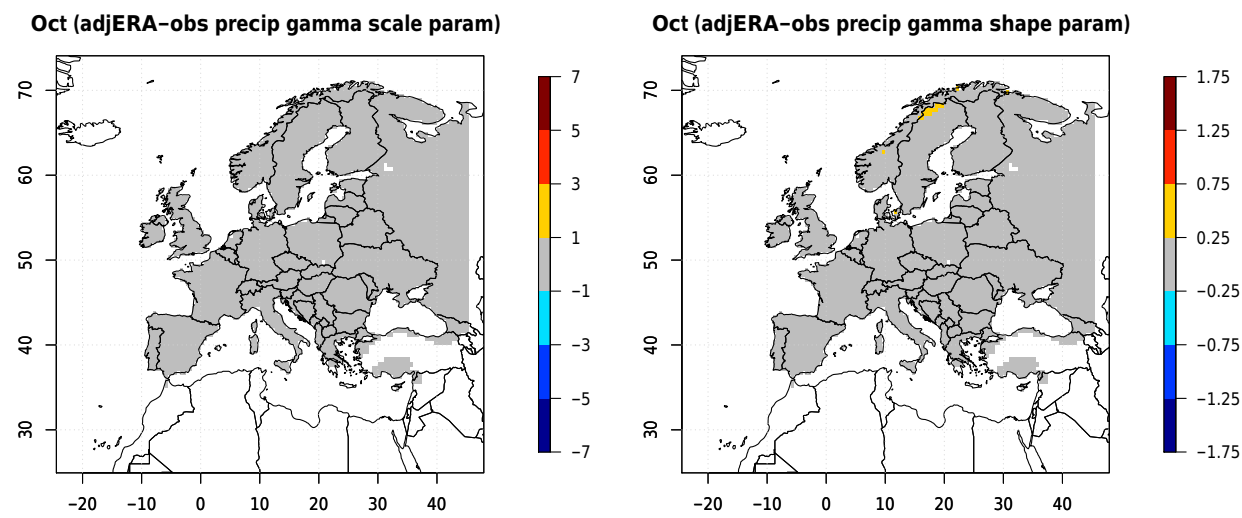

Figure 16. Differences in scale and shape parameters of the gamma distribution between bias-adjusted ERA-Interim and E-OBS for precipitation daily totals $>1 \mathrm{~mm}$. Based on daily precipitation totals for October for 1981-2010.

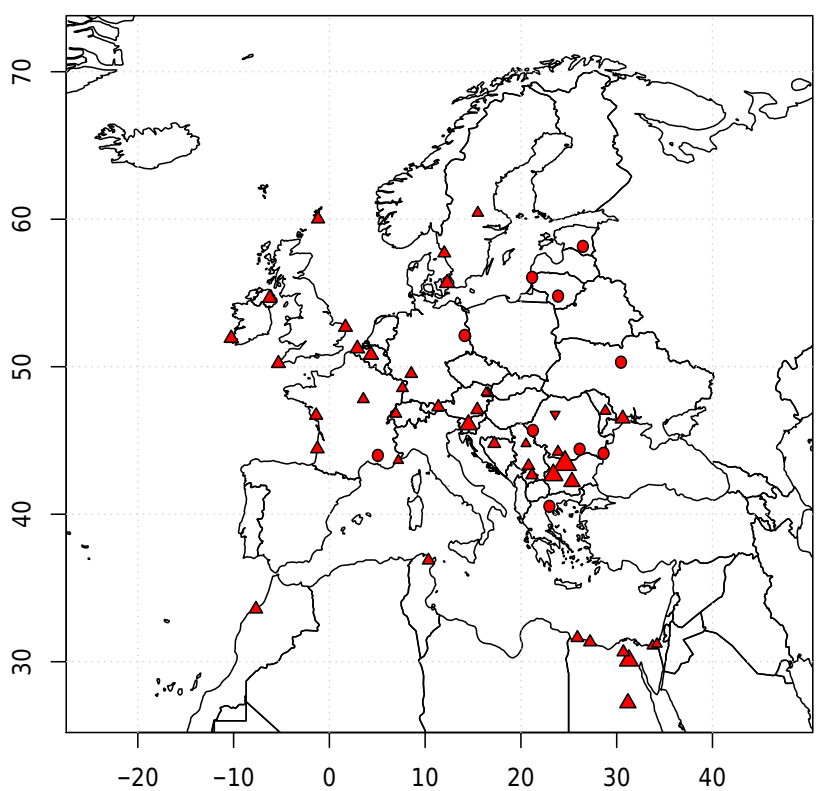

Figure 17. Bias for ERA-Interim vs. ground observations of daily mean of surface solar irradiance for 57 stations. Downward triangles mean a negative bias less than $-5 \mathrm{~W} \mathrm{~m}^{-2}$, upward triangles mean a positive bias greater than $5 \mathrm{Wm}^{-2}$, and circles mean an absolute value of the bias less than $5 \mathrm{~W} \mathrm{~m}^{-2}$. The size of the triangles increases with increasing absolute value of the bias.

choices (e.g. the CRU TS dataset used by WFDEI for air temperature or the GPCC dataset used by WFDEI for precipitation totals). If our approach is used where a dataset of the quality and temporal resolution of E-OBS is not available, it would be necessary to use the WFDEI monthly-timescale approach.

For air temperature, differences between our adjusted ERA-Interim and E-OBS are mostly within $\pm 1^{\circ} \mathrm{C}$ except at a few locations (Scandinavian mountains, southern Spain, parts of Italy, the Balkans, and Turkey), more so in May

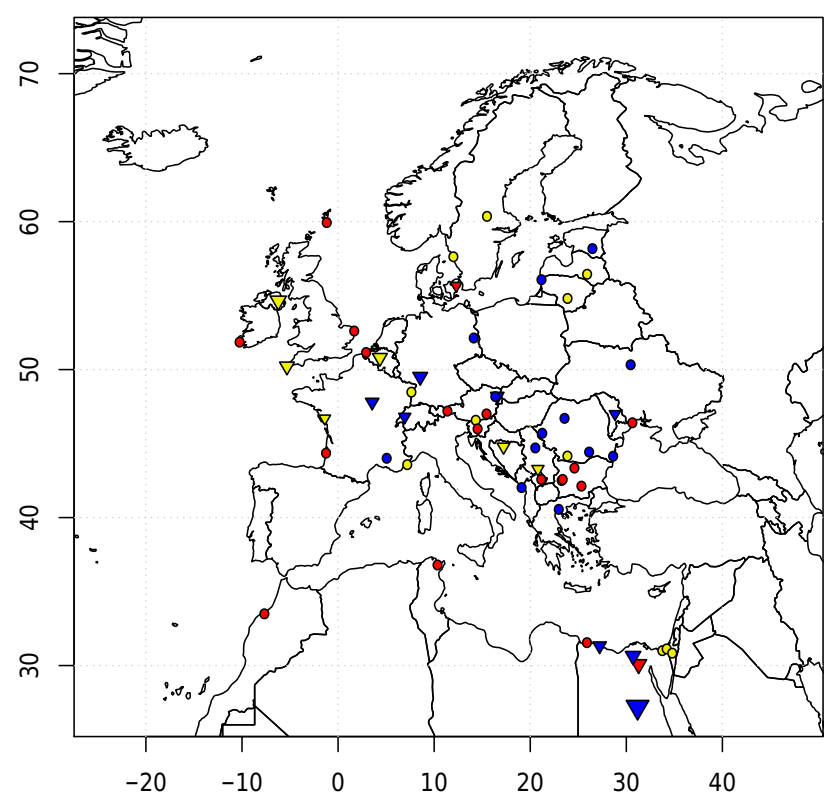

Figure 18. Improvement of bias after bias adjustment for daily mean of surface solar irradiance. Absolute values of the bias after adjustment are coded in three colours: blue for absolute value $<5 \mathrm{Wm}^{-2}$, yellow for $5<$ value $<10 \mathrm{Wm}^{-2}$, and red for value $>10 \mathrm{~W} \mathrm{~m}^{-2}$. A change in bias is coded by symbols: a circle for changes in absolute value less than $5 \mathrm{~W} \mathrm{~m}^{-2}$, a downward triangle for improvement in bias, and an upward triangle for degradation. The size of the triangles increases with increasing absolute value of the bias.

to August than in other months. Differences cover all of Turkey and are related to an almost total lack of daily observational data for Turkey within E-OBS. Additionally, most of the $\geq 1{ }^{\circ} \mathrm{C}$ differences that do occur are positive, so our adjusted ERA-Interim is slightly warmer than E-OBS. For the WFDEI minus E-OBS difference maps, there is always more colour implying greater differences, which are located more in mountainous regions and also near some northern coasts. 

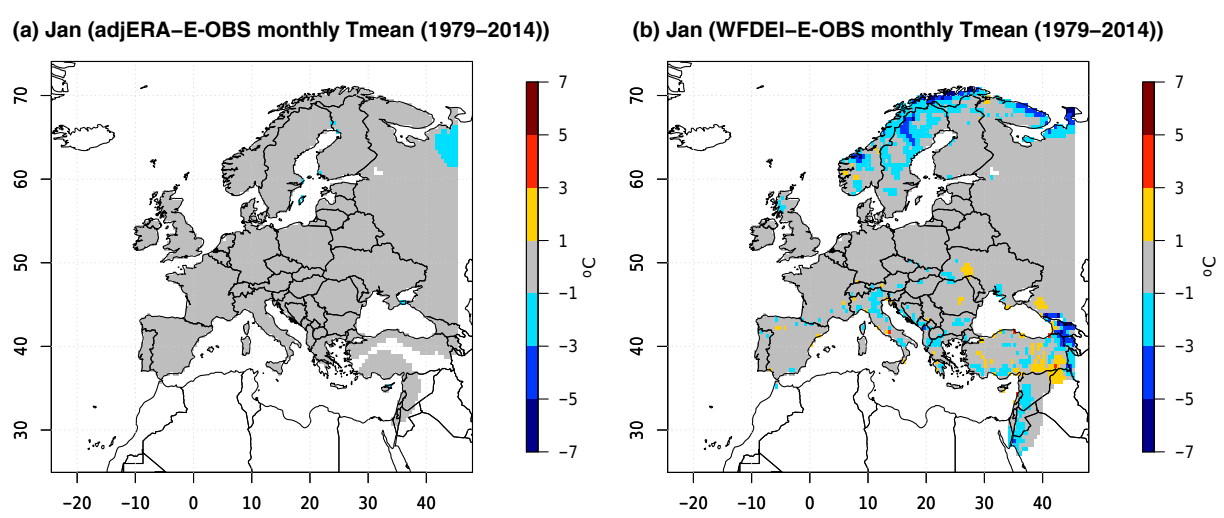

Figure 19. (a) Air temperature differences between adjusted ERA-Interim and E-OBS for January of the years 1979-2014 and (b) as (a) but differences between WFDEI and E-OBS for January of the years 1979-2014.
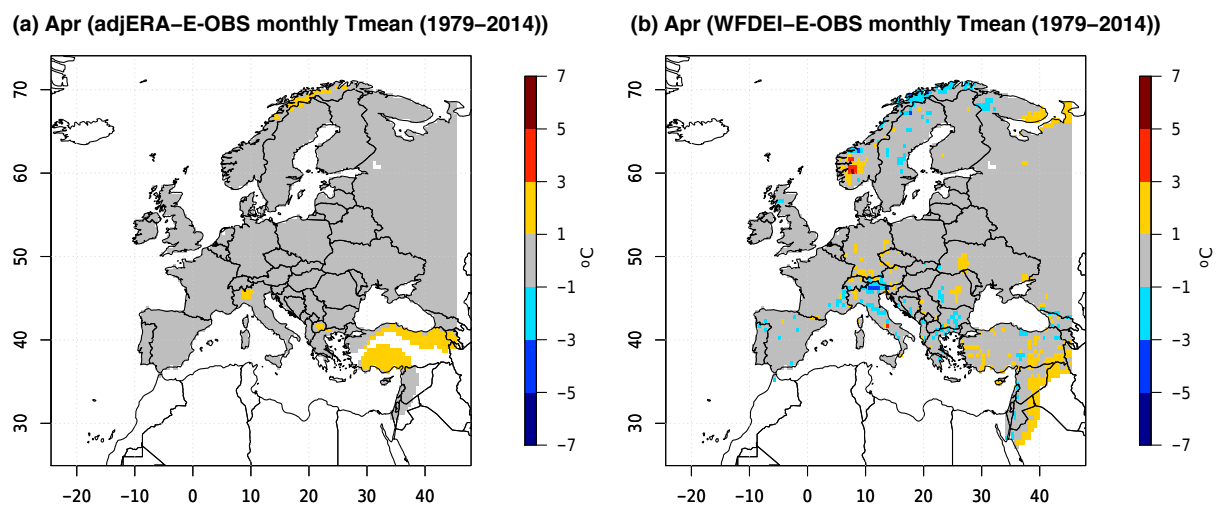

Figure 20. (a) Air temperature differences between adjusted ERA-Interim and E-OBS for April of the years 1979-2014; (b) as (a) but showing differences between WFDEI and E-OBS for April of the years 1979-2014.
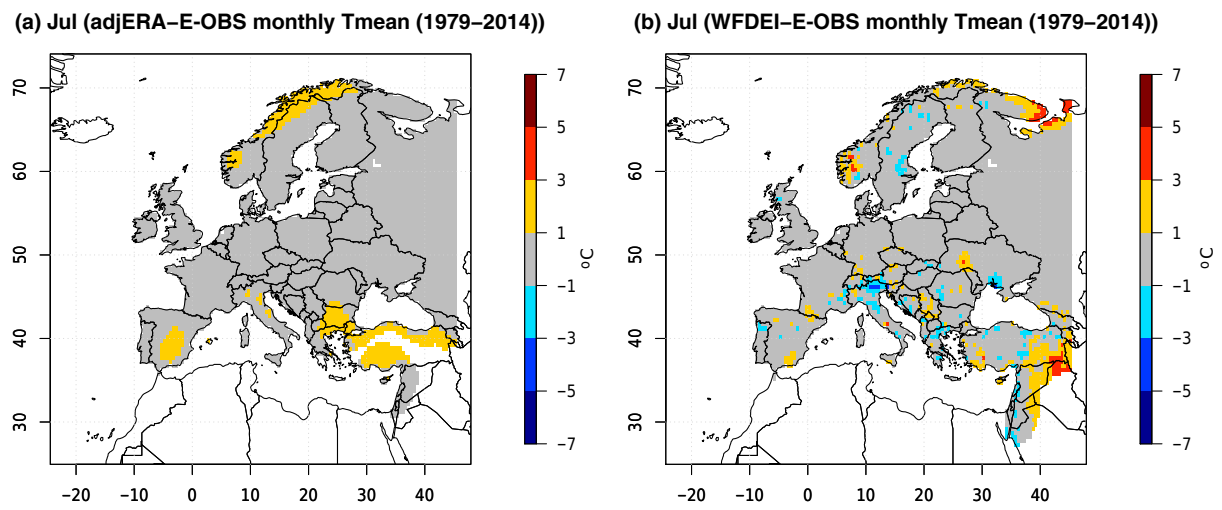

Figure 21. (a) Air temperature differences between adjusted ERA-Interim and E-OBS for July of the years 1979-2014; (b) as (a) but showing differences between WFDEI and E-OBS for July of the years 1979-2014. 

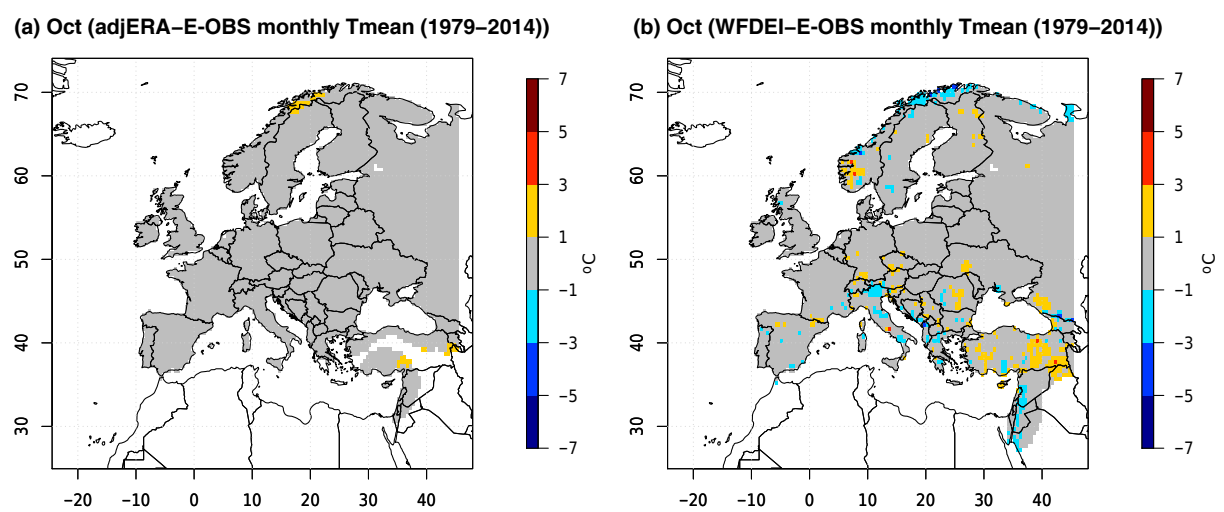

Figure 22. (a) Air temperature differences between adjusted ERA-Interim and E-OBS for October of the years 1979-2014; (b) as (a) but showing differences between WFDEI and E-OBS for October of the years 1979-2014.
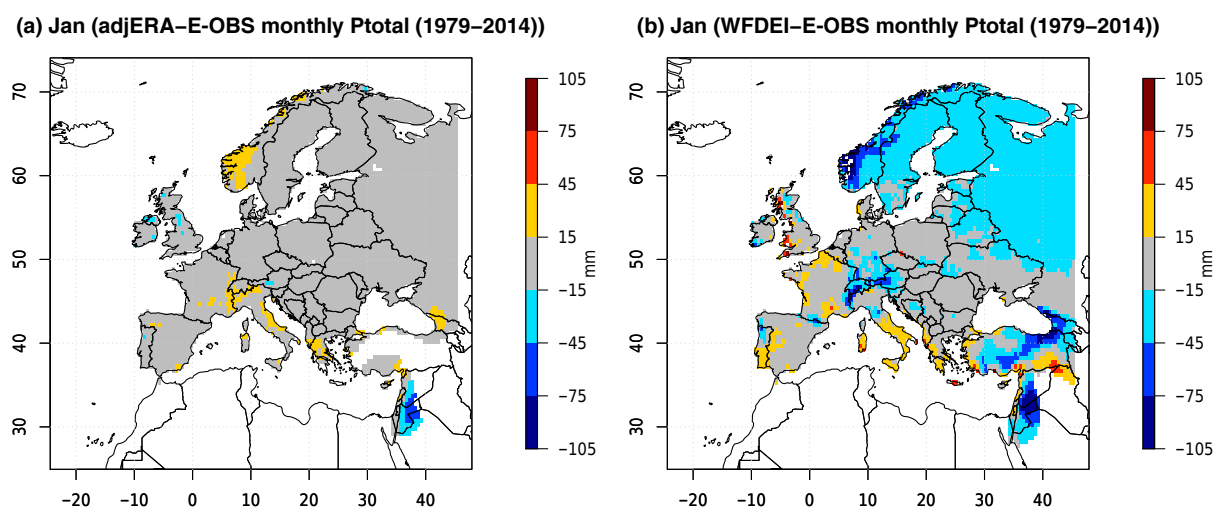

Figure 23. (a) Precipitation total differences between adjusted ERA-Interim and E-OBS for January of the years 1979-2014; (b) as (a) but showing differences between WFDEI and E-OBS for January of the years 1979-2014.
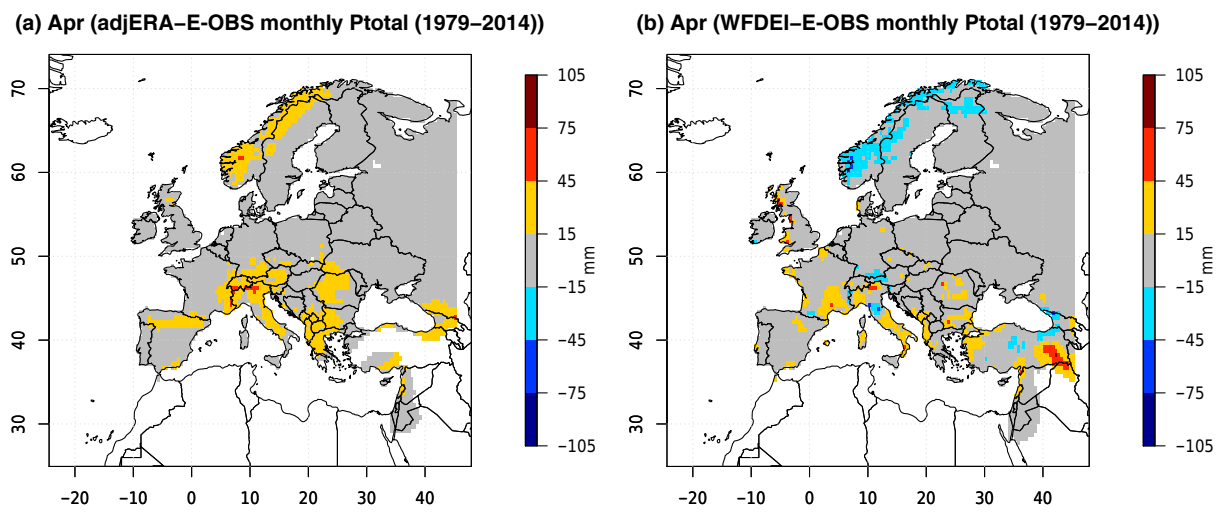

Figure 24. (a) Precipitation total differences between adjusted ERA-Interim and E-OBS for April of the years 1979-2014; (b) as (a) but showing differences between WFDEI and E-OBS for April of the years 1979-2014. 
(a) Jul (adjERA-E-OBS monthly Ptotal (1979-2014))

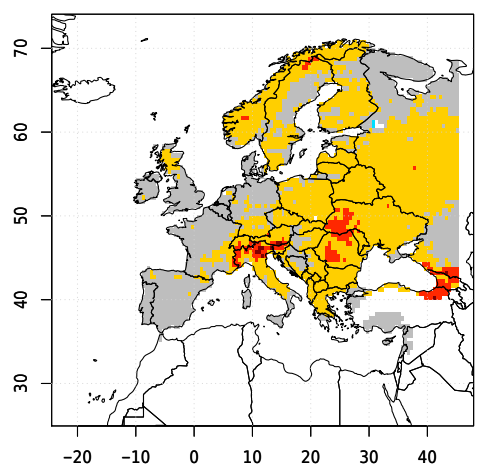

(b) Jul (WFDEI-E-OBS monthly Ptotal (1979-2014))
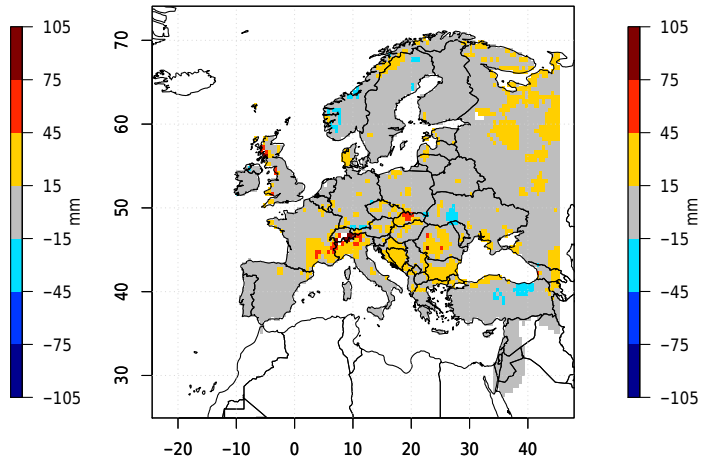

Figure 25. (a) Precipitation total differences between adjusted ERA-Interim and E-OBS for July of the years 1979-2014; (b) as (a) but showing differences between WFDEI and E-OBS for July of the years 1979-2014.

(a) Oct (adjERA-E-OBS monthly Ptotal (1979-2014))

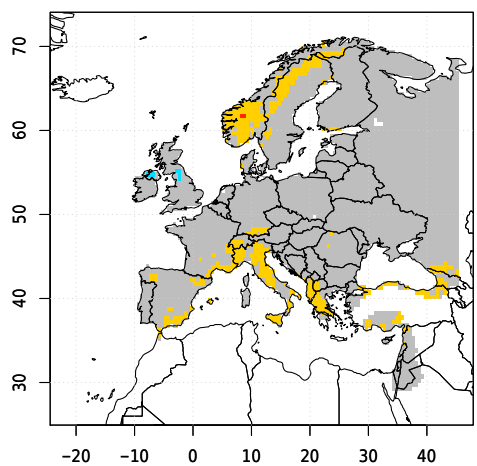

(b) Oct (WFDEI-E-OBS monthly Ptotal (1979-2014))

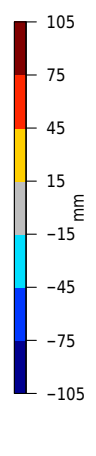

Figure 26. (a) Precipitation total differences between adjusted ERA-Interim and E-OBS for October of the years 1979-2014; (b) as (a) but showing differences between WFDEI and E-OBS for October of the years 1979-2014.

The adjusted ERA-Interim differences are relatively smooth, but the WFDEI differences are often spotty, probably related to differences in elevations between WFDEI and E-OBS. As briefly discussed in Sect. 4.2, we stated that we did not consider elevation differences between our adjusted ERAInterim and E-OBS, as both grids have relatively smooth elevation fields. For each $0.5^{\circ} \times 0.5^{\circ}$ grid box of E-OBS, the temperature value is an average of the 25 interpolated values on each $0.1^{\circ}$ grid. Additionally, the elevation field is also an average of all the elevation points available within the $0.5^{\circ}$ grid.

For precipitation, the differences appear to be larger but some of this may be due to expressing the differences as precipitation totals for each month (as opposed to the daily averages for air temperature). The adjusted ERA-Interim minus E-OBS differences are greatest in the summer months and relatively small in winter months. Differences are also more positive than negative (i.e. adjusted ERA-Interim is wetter than E-OBS). Somewhat in contrast, the WFDEI differences with E-OBS are larger in the winter months compared to summer months and their tendency is for WFDEI to be drier than E-OBS. As with air temperature, the differences are spottier than for adjusted ERA-Interim. Taken overall, WFDEI appears to be slightly better than our adjusted ERAInterim for May-August, but WFDEI is markedly poorer in the other months (particularly November-March). Elevation differences (particularly over the Norwegian mountains, the Alps, and also the Caucasus) are factors, but some could be linked to differences in the elevation datasets used by E-OBS (used in this paper) and GPCC (used by WFDEI). More consideration of the differences between climatological averages (e.g. the 1979-2014 averages for E-OBS, GPCC, and CRU TS) is beyond the scope of this study. Absolute elevation values can be very dependent on the elevation dataset used (see the discussion in Danielson and Gesch, 2010).

\section{Data availability}

ERA-Interim data were downloaded from http://apps.ecmwf. int/datasets/data/interim-full-daily/levtype $=\mathrm{sfc} /$, and our regridded version at the $0.5^{\circ} \times 0.5^{\circ}$ grid is available as the original dataset (see Sect. 6). 
E-OBS for both daily air temperature and precipitation grids is available at http://www.ecad.eu/download/ ensembles/ensembles.php.

CRU for both monthly air temperature and precipitation grids (CRU TS 3.23) is available at https://crudata.uea.ac.uk/ cru/data/hrg/.

GPCC for monthly precipitation grids is available at https: //www.dwd.de/EN/ourservices/gpcc/gpcc.html.

HadISD for sub-daily station data for wind speeds, dewpoint, and air temperatures is available at http://www. metoffice.gov.uk/hadobs/hadisd/.

For all the above datasets, the data are freely available for use, but this is qualified on some sites as use is sometimes just for research and educational purposes and it may be necessary to register to gain access.

Station data for surface solar irradiance were downloaded from the website (www.wrdc.mgo.rssi.ru) of the World Radiation Data Center (WRDC) after registration. Data are available only for research and educational communities of the countries belonging to the WMO for non-commercial activities.

HelioClim-3v5 datasets were downloaded from the SoDa Service website (http://www.soda-pro.com) managed by the company Transvalor. Data are available to anyone for free for the years 2004-2006 as a GEOSS Data-CORE (GEOSS Data Collection of Open Resources for Everyone) and for a fee for the most recent years, with the amount depending on requests and requester.

\section{Discussion}

As stated earlier in the paper, the work reported here specifically targets energy sector applications; however, the bias adjustment carried out here could be applied to a wide range of potential applications. ECEM and its users plan to use both the adjusted and unadjusted ERA-Interim gridded products through ESCIIs (Energy Sector Climate Impact Indicators), which will relate the climate variables to energy-relevant indices. Whether the bias adjustments improve agreement between these ESCIIs and the direct measures of energy production (e.g. renewable energy from solar and wind farms) is a simple way of assessing their effectiveness.

The WFDEI bias-adjusted datasets (Weedon et al., 2011, 2014) are similar datasets covering a much larger region than the ECEM European window. The adjustments have been performed on a monthly basis. Comparison with EOBS shows some seasonal differences in performances between WFDEI and the proposed dataset, with our dataset being better in the September to April months. WFDEI datasets have been used extensively, based on citation counts. The proposed dataset applies adjustments to the distributions of a similar set of variables, providing daily and 6-hourly estimates. Outside the energy sector, the bias-adjusted datasets could be used for driving hydrological and land surface mod- els in a similar way to Orth and Seneviratne (2015). Our bias adjustments, therefore, could be assessed beyond the energy sector. For Europe, they could be compared with WFDEI data (often referred to as forcing data in hydrology, as opposed to bias-adjusted reanalyses) through comparison of results from hydrologic and/or crop climate models (e.g. using discharge or yield data). Bias adjustment ought to be an improvement, and this can be assessed in a similar way to the ESCIIs within ECEM.

Is there a way of simultaneously bias adjusting all variables or at least adjusting pairs to start with? Whereas Weedon et al. (2014) and this paper have not attempted multivariate adjustment, this is being tested in the ECEM project. However, as the number of variables increases, this becomes more impractical. The usefulness of all bias-adjusted datasets can be assessed through ESCIIs and discharge-yield data (i.e. using variables external to reanalysis) which would be expected to be best simulated just as if perfect observational data were available. Multivariate bias adjustment was experimented with in ECEM (using wind speed and temperature), but the results are dependent on the availability of adequate station data for variables measured together (Dekens et al., 2017). Access to data is a crucial aspect of all the datasets used in this study. ERA-Interim would be improved with greater numbers of station input data, as would E-OBS and the other data products considered in this paper. Improved access, however, is unlikely to reduce the need for bias adjustment.

\section{The ECEM dataset: its description and how to access it}

All the ERA-Interim (original and bias-adjusted) are available as netcdf files from the CDS of the Copernicus Climate Data Service. As this CDS is currently being developed, this $\mathrm{ftp}$ site (ftp://ecem.climate.copernicus.eu) can currently be used to access all files discussed in this paper. This site currently has no password, but once on the CDS, there will likely be a registration procedure. Datasets are named according to the ECEM project. The original or unadjusted filenames have "noc" in the file name. They are as follows for air temperature (T2M), dewpoint temperature (DP), solar irradiance (GHI, Global Horizontal Irradiation), wind speed (WS) and precipitation (TP):

$$
\begin{aligned}
\text { - H_ERAI_ECMW_T159_TA-_0002m_EUR1 } \\
\text { 222E27N_45W72N_050d_IN_TIM_19790101_ } \\
\text { 20161231_06h_NA-_noc_org_NA_NA-.nc } \\
\text { - H_ERAI_ECMW_T159_DP-_0002m_EUR1 } \\
\text { 222E27N_45W72N_050d_IN_TIM_19790101_ } \\
\text { 20161231_06h_NA-_noc_org_NA_NA-.nc } \\
\text { - H_ERAI_ECMW_T159_GHI_0000m_EUR1 } \\
\text { 22EE27N_45W72N_050d_IN_TIM_19790101_ } \\
\text { 20161231_03h_NA-_noc_org_NA_NA-.nc }
\end{aligned}
$$




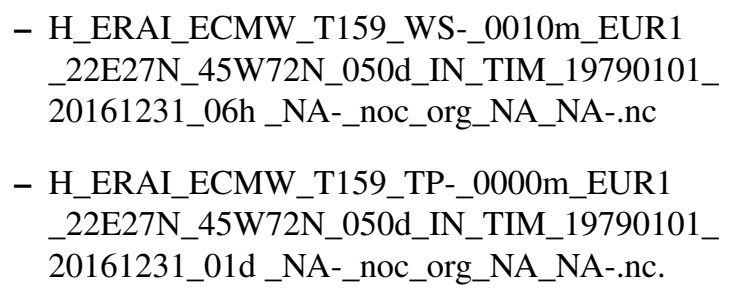

The adjusted files are labelled similarly but include the distribution and "bc" instead of "noc". So, for air temperature and dewpoint, they include "nbc", for solar irradiance "qbc", for wind speed "wbc", and for precipitation "gbc". A final file contains the bias-adjusted relative humidity file.

$$
\begin{aligned}
\text { - H_ERAI_ECMW_T159_TA-_0002m_EUR1_ } \\
\text { 22E27N_45W72N_050d_IN_TIM_19790101_ } \\
\text { 20161231_06h_NA-_nbc_org_NA_NA-.nc } \\
\text { - H_ERAI_ECMW_T159_DP-_0002m_EUR1_- } \\
\text { 22E27N_45W72N_050d_IN_TIM_19790101_ } \\
\text { 20161231_06h_NA-_nbc_org_NA_NA-.nc } \\
\text { - H_ERAI_ECMW_T159_GHI_0000m_EUR1_- } \\
\text { 22E27N_45W72N_050d_IN_TIM_19790101_ } \\
\text { 20161231_03h_NA-_qbc_org_NA_NA-.nc } \\
\text { - H_ERAI_ECMW_T159_WS-_0010m_EUR1_- } \\
\text { 22E27N_45W72N_050d_IN_TIM_19790101_- } \\
\text { 20161231_06h_NA-_wbc_org_NA_NA-.nc } \\
\text { - H_ERAI_ECMW_T159_TP-_0000m_EUR1_ } \\
\text { 22E27N_45W72N_050d_IN_TIM_19790101_- } \\
\text { 20161231_01d_NA-_gbc_org_NA_NA-.nc } \\
\text { - H_ERAI_ECMW_T159_RH-_0002m_EUR1_ } \\
\text { 22E27N_45W72N_050d_DR_TIM_19790101_ } \\
\text { 20161231_06h_NA-_nbc_org_NA_NA-.nc }
\end{aligned}
$$

Two example locations for each variable of the distributional comparisons are given in the paper (Figs. 2, 3, 6, 7, 10, 11, 14, and 15). The ftp site also includes all the distributional comparisons as pdfs, with the stations ordered by their WMO number when comparing with HadISD and by latitude and then longitude when comparing with E-OBS. These files have the following names, for air temperature (Tmean), dewpoint temperature, wind speed (WS), and precipitation (dly_precip), respectively:

$$
\begin{aligned}
& \text { - adjERA_and_ERA_vs_EOBS_dly_Tmean_PDFs_1981-2010.pdf } \\
& \text { - adjERA_and_ERA_vs_HadISD_dly_DPD_PDFs_1981-2010.pdf } \\
& \text { - adjERA_and_ERA_vs_EOBS_dly_precip_PDFs_1981-2010_1p0.pdf } \\
& \text { - adjERA_and_ERA_vs_HadISD_ws_PDFs_1981-2010.pdf. }
\end{aligned}
$$

Additionally, the ftp site includes all 12 monthly difference plots, which are shown in Figs. 19-26 for the mid-season months:
- adjERA-EOBS_Tmean_monthly_deltas_means.pdf

- adjERA-EOBS_Precip_monthly_deltas_means.pdf

- WFDEI-EOBS_Tmean_monthly_deltas_means.pdf

- WFDEI-EOBS_Precip_monthly_deltas_means.pdf.

Competing interests. The authors declare that they have no conflict of interest.

Acknowledgements. The authors would like to acknowledge funding for the European Climatic Energy Mixes (ECEM) project by the Copernicus Climate Change Service, a programme being implemented by the European Centre for Medium-Range Weather Forecasts (ECMWF) on behalf of the European Commission. The specific grant number is 2015/C3S_441_Lot2_UEA. The authors particularly thank the reviewers (Graham Weedon and Helge Goessling) for their extensive and thoughtful reviews, which have significantly improved the paper. The authors also thank Robert Dunn from the UK MetOffice Hadley Centre who kindly extracted the wind speed, dewpoint, and air temperature for all European stations from the HadISD dataset. The authors thank all ground station operators of the WMO network for their valuable measurements. They additionally thank the World Radiation Data Centre for hosting a website for downloading data. The authors thank the French company Transvalor, which takes care of the SoDa Service for the common good, thus providing an efficient access to the HelioClim databases.

Edited by: Gert König-Langlo

Reviewed by: Graham Weedon and Helge Goessling

\section{References}

Becker, A., Finger, P., Meyer-Christoffer, A., Rudolf, B., Schamm, K., Schneider, U., and Ziese, M.: A description of the global land-surface precipitation data products of the Global Precipitation Climatology Centre with sample applications including centennial (trend) analysis from 1901-present, Earth Syst. Sci. Data, 5, 71-99, https://doi.org/10.5194/essd-5-71-2013, 2013.

Blanc, P., Gschwind, B., Lefèvre, M., and Wald, L.: The HelioClim project: Surface solar irradiance data for climate applications, Remote Sensing, 3, 343-361, https://doi.org/10.3390/rs3020343, 2011.

Bojinski, S., Verstraete, M., Peterson, T. C., Richter, C., Simmons, A., and Zemp, M.: The concept of essential climate variables in support of climate research, applications, and policy, B. Am. Meteor. Soc., 95, 1431-1443, https://doi.org/10.1175/BAMS-D-1300047.1, 2014.

Boilley, A. and Wald, L.: Comparison between meteorological reanalyses from ERA-Interim and MERRA and measurements of daily solar irradiation at surface, Renew. Energ., 75, 135-143, https://doi.org/10.1016/j.renene.2014.09.042, 2015.

Compo, G. P., Whitaker, J. S., Sardeshmukh, P. D., Matsui, N., Allan, R. J., Yin, X., Gleason Jr., B. E., Vose, R. S., Rutledge, G., Bessemoulin, P., Brönnimann, S., Brunet, M., Crouthamel, R. I., 
Grant, A. N., Groisman, P. Y., Jones, P. D., Kruk, M. C., Kruger, A. C., Marshall, G. J., Maugeri, M., Mok, H. Y., Nordli, Ø., Ross, T. F., Trigo, R. M., Wang, X. L., Woodruff, S. D., and Worley, S. J.: The twentieth century reanalysis project, Q. J. Roy. Meteor. Soc., 137, 1-28, https://doi.org/10.1002/qj.776, 2011.

Cosgrove, B. A., Lohmann, D., Mitchell, K. E., Houser, P. R., Wood, E. F., Schaake, J. C., Robock, A., Marshall, C., Sheffield, J., Duan, Q., Luo, L., Wayne Higgins, R., Pinker, R. T., Dan Tarpley, J., and Meng, J.: Real-time and retrospective forcing in the North American Land Data Assimilation System (NLDAS) project, J. Geophys. Res., 108, 8842, https://doi.org/10.1029/2002JD003118, 2003.

Danielson, J. J. and Gesch, D. B.: Global multi-resolution terrain elevation data 2010 (GMTED2010): U.S. Geological Survey Open-File Report 2011-1073, 26 pp, 2011.

Dee, D. P., Uppala, S. M., Simmons, A. J., Berrisford, P., Poli, P., Kobayashi, S., Andrae, U., Balmaseda, M. A., Balsamo, G., Bauer, P., Bechtold, P., Beljaars, A. C. M., van de Berg, L., Bidlot, J., Bormann, N., Delsol, C., Dragani, R., Fuentes, M., Geer, A. J., Haimberger, L., Healy, S. B., Hersbach, H., Hólm, E. V., Isaksen, L., Kållberg, P., Köhler, M., Matricardi, M., McNally, A. P., Monge-Sanz, B. M., Morcrette, J.-J., Park, B.-K., Peubey, C., de Rosnay, P., Tavolato, C., Thépaut, J.-N., and Vitart, F.: The ERA-Interim reanalysis: configuration and performance of the data assimilation system, Q. J. Roy. Meteor. Soc., 137, 553-597, https://doi.org/10.1002/qj.828, 2011.

Dekens, L., Parey, S., Grandjacques, M., and Dacunha-Castelle, D.: Multivariate distribution correction of climate model outputs: a generalisation of quantile mapping approaches, Environmetrics, https://doi.org/10.1002/env.2454, online first, 2017.

Dunn, R. J. H., Willett, K. M., Thorne, P. W., Woolley, E. V., Durre, I., Dai, A., Parker, D. E., and Vose, R. S.: HadISD: a qualitycontrolled global synoptic report database for selected variables at long-term stations from 1973-2011, Clim. Past, 8, 1649-1679, https://doi.org/10.5194/cp-8-1649-2012, 2012.

Dunn, R. J. H., Willett, K. M., Morice, C. P., and Parker, D. E.: Pairwise homogeneity assessment of HadISD, Clim. Past, 10, 15011522, https://doi.org/10.5194/cp-10-1501-2014, 2014.

Eissa, Y., Korany, M., Aoun, Y., Boraiy, M., Abdel Wahab, M., Alfaro, S., Blanc, P., El-Metwally, M., Ghedira, H., and Wald, L.: Validation of the surface downwelling solar irradiance estimates of the HelioClim-3 database in Egypt, Remote Sensing, 7, 9269 9291, https://doi.org/10.3390/rs70709269, 2015.

Gudmundsson, L., Bremnes, J. B., Haugen, J. E., and EngenSkaugen, T.: Technical Note: Downscaling RCM precipitation to the station scale using statistical transformations - a comparison of methods, Hydrol. Earth Syst. Sci., 16, 3383-3390, https://doi.org/10.5194/hess-16-3383-2012, 2012.

Harpham, C., Troccoli, A., Jones, P., Ranchin, T., and Wald, L.: Comparing monthly statistical distributions of wind speed measured at wind towers and estimated from ERA-Interim, 16th EMS Annual Meeting, 12-16 September 2016, Trieste, Italy, EMS Annual Meeting Abstracts, 13, EMS2016-336, 2016.

Harris, I., Jones, P. D., Osborn, T. J., and Lister, D. H.: Updated high-resolution monthly grids of monthly climatic observations: the CRU TS 3.10 dataset, Int. J. Climatol., 34, 623-642, https://doi.org/10.1002/joc.3711, 2014.

Haylock, M. R., Hofstra, N., Klein Tank, A. M. G., Klok, E. J., Jones, P. D., and New, M.: A European daily high-resolution gridded dataset of surface temperature and precipitation, J. Geophys. Res., 113, D20119, https://doi.org/10.1029/2008JD010201, 2008.

Hersbach, H., Peubey, C., Simmons, A., Berrisford, P., Poli, P., and Dee, D.: ERA-20CM: a twentieth-century atmospheric model ensemble, Q. J. Roy. Meteor. Soc., 141, 2350-2375, https://doi.org/10.1002/qj.2528, 2015.

Horton, E. B., Folland, C. K., and Parker, D. E.: The changing incidence of extremes in worldwide and Central England temperatures to the end of the twentieth century, Climatic Change, 50, 267-295, 2001.

Jones, P. D.: The Reliability of Global and Hemispheric Surface Temperature Records, Adv. Atmos. Sci., 33, 269-282, https://doi.org/10.1007/s00376-015-5194-4, 2016.

Maraun, D.: Nonstationarities of regional climate model biases in European seasonal mean temperature and precipitation sums, Geophys. Res. Lett., 39, L06706, https://doi.org/10.1029/2012GL051210, 2012.

Maraun, D.: Bias correction, quantile mapping, and downscaling: revisiting the inflation issue, J. Climate, 26, 2137-2143, https://doi.org/10.1175/JCLI-D-12-00821.1, 2013.

Maraun, D., Wetterhall, F., Ireson, A. M., Chandler, R. E., Kendon, E. J., Widmann, M., Brienen, S., Rust, H. W., Sauter, M., Themeß1, T., Venema, V. K. C., Chun, K. P., Goodess, C. M., Jones, R. G., Onof, C., Vrac, M., and Thiele-Eich, I.: Precipitation downscaling under climate change. Recent developments to bridge the gap between dynamical models and the end user, Rev. Geophys., 48, RG3003, https://doi.org/10.1029/2009RG000314, 2010.

Marchand, M., Al-Azri, N., Ombe-Ndeffotsing, A., Wey, E., and Wald, L.: Evaluating meso-scale change in performance of several databases of hourly surface irradiation in South-eastern Arabic Pensinsula, Adv. Sci. Res., 14, 7-15, https://doi.org/10.5194/asr-14-7-2017, 2017.

Orth, R. and Seneviratne, S.I.: Introduction of a simple-modelbased land surface dataset for Europe, Environ. Res. Lett., 10, 044012, https://doi.org/10.1088/1748-9326/10/4/044012, 2015.

Oyerinde, G. T., Hountondji, F. C. C., Lawin, A. E., Odofin, A. J., Afouda, A., and Diekkrüger, B.: Improving hydro-climate projections with bias-correction in Sahelian Niger basin, West Africa, Climate, 5, 8, https://doi.org/10.3390/cli5010008, 2017.

Piani, C., Haerter, J. O., and Coppola, E.: Statistical bias correction for daily precipitation in regional climate models over Europe, Theor. Appl. Climatol., 99, 187-192, 2010a.

Piani, C., Weedon, G., Best, M., Gomes, S., Viterbo, P., Hagemann, S., and Haerter, J.: Statistical bias correction of global simulated daily precipitation and temperature for the application of hydrological models, J. Hydrol., 395, 199-215, https://doi.org/10.1016/j.jhydrol.2010.10.024, 2010b.

Rienecker, M. M., Suarez, M. J., Gelaro, R., Todling, R., Bacmeister, J., Liu, E., Bosilovich, M. G., Schubert, S. D., Takacs, L., Kim, G., Bloom, S., Chen, J., Collins, D., Conaty, A., da Silva, A., Gu, W., Joiner, J., Koster, R. D., Lucchesi, R., Molod, A., Owens, T., Pawson, S., Pegion, P., Redder, C. R., Reichle, R., Robertson, F. R., Ruddick, A. G., Sienkiewicz, M., and Woollen, J.: MERRA: NASA's Modern-Era Retrospective Analysis for Research and Applications, J. Climate, 24, 3624-3648, https://doi.org/10.1175/JCLI-D-11-00015.1, 2011. 
Rigollier, C., Lefèvre, M., and Wald, L.: The method Heliosat-2 for deriving shortwave solar radiation from satellite images, Sol. Energy, 77, 159-169, https://doi.org/10.1016/j.solener.2004.04.017, 2004.

Sheffield, J., Goteti, G., and Wood, E. F.: Development of a 50-yr high-resolution global dataset of meteorological forcings for land surface modeling, J. Climate, 19, 3088-3111, 2006.

Simmons, A. J., Berrisford, P., Dee, D. P., Hersbach, H., Hirahara, S., and Thépaut, J.-N.: A reassessment of temperature variations and trends from global reanalyses and monthly surface climatological datasets, Q. J. Roy. Meteor. Soc., 143: 101-119, https://doi.org/10.1002/qj.2949, 2017.

Smith, A., Lott, N., and Vose, R.: The Integrated Surface Database: Recent Developments and Partnerships, B. Am. Meteorol. Soc., 92, 704-708, https://doi.org/10.1175/2011BAMS3015.1, 2011.

Themeß1, M. J., Gobiet, A., and Leuprecht, A.: Empirical-statistical downscaling and error correction of daily precipitation from regional climate models, Int. J. Climatol., 31, 1530-1544, https://doi.org/10.1002/joc.2168, 2011.

Themeß1, M. J., Gobiet, A., and Heinrich, G.: Empirical-statistical downscaling and error correction of regional climate models and its impact on the climate change signal, Climatic Change, 112, 449-468, https://doi.org/10.1007/s10584-011-0224-4, 2012.

Thomas, C., Wey, E., Blanc, P., and Wald, L.: Validation of three satellite-derived databases of surface solar radiation using measurements performed at 42 stations in Brazil, Adv. Sci. Res., 13, 129-136, https://doi.org/10.5194/asr-13-129-2016, 2016a.

Thomas, C., Wey, E., Blanc, P., Wald, L., and Lefèvre, M.: Validation of HelioClim-3 version 4, HelioClim-3 version 5 and MACC-RAD using 14 BSRN stations, 2015 Solar Heating and Cooling, Energy Procedia, 91, 1059-1069, 2016b.

Tye, M. R., Stephenson, D. B., Holland, G. J., and Katz, R. W.: A Weibull approach for improving climate model projections of tropical cyclone wind-speed distributions, J. Climate, 27, 61196133, https://doi.org/10.1175/JCLI-D-14-00121.1, 2014.
Vrac, M. and Friederichs, P.: Multivariate-intervariable, spatial, and temporal-bias correction, J. Climate, 28, 218-237, https://doi.org/10.1175/JCLI-D-14-00059.1, 2015.

Vrac, M., Drobinski, P., Merlo, A., Herrmann, M., Lavaysse, C., Li, L., and Somot, S.: Dynamical and statistical downscaling of the French Mediterranean climate: uncertainty assessment, Nat. Hazards Earth Syst. Sci., 12, 2769-2784, https://doi.org/10.5194/nhess-12-2769-2012, 2012.

Weedon, G. P., Gomes, S., Viterbo, P., Österle, H., Adam, J.C., Bellouin, N., Boucher, O. and M. Best, M.: The WATCH forcing data 1958-2001: A meteorological forcing dataset for land surface and hydrological models, Technical Report No. 22, 41 pp., available at: http://www.eu-watch.org/media/default.aspx/emma/org/ 10376311/, last access: 3 July 2017, 2010

Weedon, G. P., Gomes, S., Viterbo, P., Shuttleworth, W. J., Blyth, E., Osterle, H., Adam, J. C., Bellouin, N., Boucher, O., and Best, M.: Creation of the WATCH forcing data and its use to assess global and regional reference crop evaporation over land during the twentieth century, J. Hydrometeorol., 12, 823-848, https://doi.org/10.1175/2011JHM1369.1, 2011.

Weedon, G. P., Balsamo, G., Bellouin, N., Gomes, S., Best, M. J., and Viterbo, P.: The WFDEI meteorological forcing data set: WATCH Forcing Data methodology applied to ERAInterim reanalysis data, Water Resour. Res., 50, 7505-7514, https://doi.org/10.1002/2014WR015638, 2014.

Wilcke, R., Mendlik, T., and Gobiet, A.: Multi-variable error correction of regional climate models, Climatic Change, 120, 871-887, https://doi.org/10.1007/s10584-013-0845-x, 2013

Wilks, D. S.: tatistical Methods in Atmospheric Sciences, Academic, New York, 467 pp., 1995.

Yang, W., Andreasson, J., Graham, L. P., Olsson, J., Rosberg, J., and Wetterhall, D.: Distribution-based scaling to improve usability of regional climate model projections for hydrological climate change impacts studies, Hydrol. Res., 41, 3-4, https://doi.org/10.2166/nh.2010.004, 2010. 